\title{
RASA1 regulates the function of lymphatic vessel valves in mice
}

\author{
Philip E. Lapinski, ${ }^{1}$ Beth A. Lubeck,, ${ }^{1}$ Di Chen, ${ }^{1}$ Abbas Doosti, ${ }^{1}$ Scott D. Zawieja, ${ }^{2}$ Michael J. Davis, ${ }^{2}$ and Philip D. King ${ }^{1}$ \\ 'Department of Microbiology and Immunology, University of Michigan Medical School, Ann Arbor, Michigan, USA. ²Department of Medical Pharmacology and Physiology, University of Missouri, \\ Columbia, Missouri, USA
}

\begin{abstract}
Capillary malformation-arteriovenous malformation (CM-AVM) is a blood and lymphatic vessel (LV) disorder that is caused by inherited inactivating mutations of the RASA1 gene, which encodes p120 RasCAP (RASA1), a negative regulator of the Ras small CTP-binding protein. How RASA1 mutations lead to the LV leakage defects that occur in CM-AVM is not understood. Here, we report that disruption of the Rasa1 gene in adult mice resulted in loss of LV endothelial cells (LECs) specifically from the leaflets of intraluminal valves in collecting LVs. As a result, valves were unable to prevent fluid backflow and the vessels were ineffective pumps. Furthermore, disruption of Rasa1 in midgestation resulted in LEC apoptosis in developing LV valves and consequently failed LV valvulogenesis. Similar phenotypes were observed in induced RASA1-deficient adult mice and embryos expressing a catalytically inactive RASA1 ${ }^{\mathrm{R} 7800}$ mutation. Thus, RASA1 catalytic activity is essential for the function and development of LV valves. These data provide a partial explanation for LV leakage defects and potentially other LV abnormalities observed in CM-AVM.
\end{abstract}

\section{Introduction}

Capillary malformation-arteriovenous malformation (CM-AVM) is an autosomal dominant vascular disorder that affects at least 1:100,000 individuals in Northern European populations (1-3). The pathognomonic feature of CM-AVM is the presence of 1 or more small randomly distributed cutaneous CMs. In one-third of patients, there are additional fast flow blood vascular (BV) lesions, such as AVM, arteriovenous fistulas (AVF), or Parkes Weber syndrome, in which AVF and CM are associated with overgrowth of a single limb. Lymphatic vessel (LV) disorders have also been described in some CM-AVM patients. These include chylothorax and chylous ascites (accumulation of lymph in the pleural and peritoneal cavities, respectively), lymphedema, LV malformation, and hyperplasia (2-6). In 70\% of CM-AVM patients, inherited inactivating mutations of the RASA1 gene are responsible for disease development. RASA1 is a Ras GTPase-activating protein (RasGAP) that accelerates conversion of the inner membranetethered Ras protein from an active GTP-bound state back to an inactive GDP-bound state during growth factor receptor signal transduction (7). In addition, RASA1 has been reported to perform distinct functions in intracellular signal transduction that are independent of its ability to promote Ras hydrolysis of $\operatorname{GTP}(7,8)$.

Germline RASA1 mutations in CM-AVM span the entire gene, and the vast majority are nonsense mutations, splice site substitutions, or insertions or deletions that are all predicted to result in rapid RNA transcript degradation as a consequence of nonsense-mediat-

Authorship note: M.J. Davis and P.D. King contributed equally to this work. Conflict of interest: The authors have declared that no conflict of interest exists. Submitted: July 18, 2016; Accepted: March 23, 2017.

Reference information: J Clin Invest. 2017;127(7):2569-2585.

https://doi.org/10.1172/JCl89607. ed RNA decay (9). In affected families with RASA1 mutations, 95\% of individuals that inherit a mutated RASA1 gene develop vascular lesions, attesting to the high penetrance of these mutations (1-3). It has been proposed that development of vascular lesions in patients with germline RASA1 mutations additionally requires somatic mutation of the inherited normal RASA1 allele, resulting in the complete loss of RASA1 protein in affected cells $(2,3)$. In support of this hypothesis, a RASA1 somatic mutation was recently identified in a CM of a CM-AVM patient with an inherited RASA1 mutation (5).

Consistent with the vascular anomalies in humans with RASA1 mutations, homozygous Rasa1-null mice show defects in vascular development and die in midgestation (10). In the yolk sac, newly formed BV endothelial cells (BECs) fail to organize into a vascular network that supplies blood to the embryo. In the embryo proper, the developing dorsal aorta is irregular, with abnormal projecting arteries and local hemorrhage, and distension of the pericardial sac is observed. The same phenotype is observed in mice in which the Rasa1 gene is disrupted specifically in BECs, showing that the $\mathrm{BV}$ abnormalities that occur in global Rasa1-null mice are intrinsic to BECs (11). Furthermore, the same BV abnormalities occur in homozygous Rasa1 ${ }^{R 780 Q}$ mice, which express a mutant RASA1 protein that is incapacitated in its ability to negatively regulate Ras specifically (12). Thus, BV abnormalities in Rasa1 null mice result from loss of RASA1-mediated control of Ras signaling rather than loss of noncatalytic functions of RASA1.

Induced disruption of the Rasa1 gene in adult mice does not result in spontaneous BV abnormalities, but instead causes a striking LV defect that parallels the LV abnormalities seen in some CM-AVM patients (11). Starting at 1 to 2 months after gene disruption, mice develop chylothorax and chylous ascites and succumb to the former. Mice also develop extensive LV hyperplasia, particularly at the end stage of disease. These lymphatic phenotypes 
A Rasa1 ${ }^{f l i f l}(9 \mathrm{wk})$
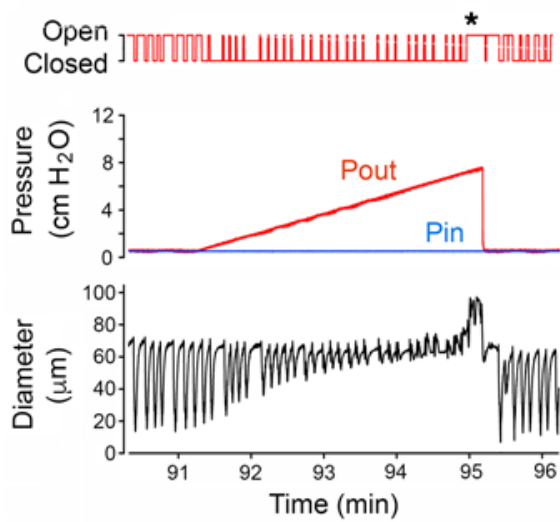

Rasa1 ${ }^{f / f f l} U b^{\text {ert2cre }}(9 \mathrm{wk})$
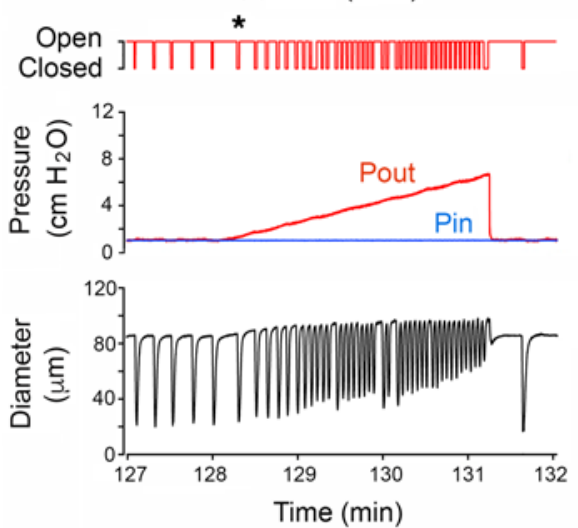

$\operatorname{Rasa1}^{f l f l}(9 \mathrm{wk})$

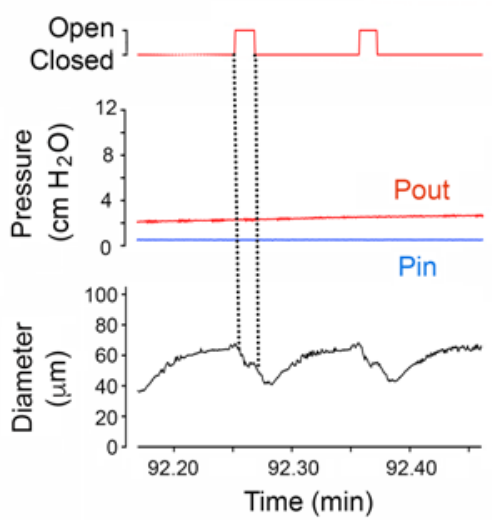

Rasa1 ${ }^{f l / f l} U b^{\text {ert2cre }}(9 \mathrm{wk})$

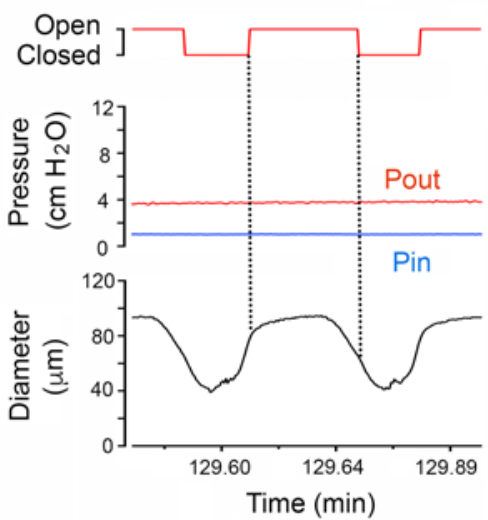

B

9 wk after tamoxifen

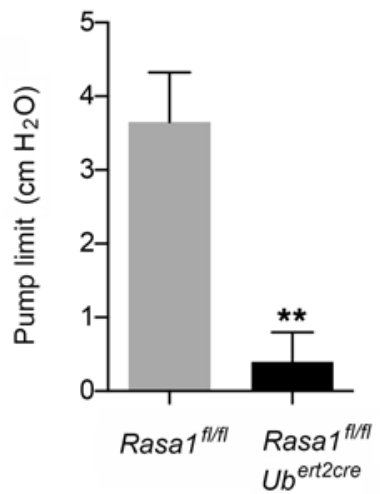

Figure 1. Impaired pumping function of induced RASA1-deficient LVs. (A) Examples of traces from pump function assays performed with LVs from littermate Rasa $f^{f / f l}$ and Rasa ${ }^{f / / f l} U b^{\text {ertzcre }}$ mice treated with tamoxifen 9 weeks beforehand. Tests were performed as indicated for contraction assays in Supplemental Figure 1 except that $P_{\text {in }}$ was kept at $0.5 \mathrm{~cm} \mathrm{H}_{2} \mathrm{O}$ as $\mathrm{P}_{\text {out }}$ was increased from 0.5 to $10 \mathrm{~cm} \mathrm{H}_{2} \mathrm{O}$ in ramp-wise fashion. The position of the downstream valve as open or closed is shown at top. In traces at left, asterisks indicate the point of pump failure where the downstream valve locks, at least temporarily, into an open position. Traces at right show magnified regions from left traces near the beginning of the $P_{\text {out }}$ ramps. Drop-down dotted lines are to illustrate at which point in the vessel contraction cycle valves open. Note valve opening during systole in the Rasa $7^{f / f f}$ vessel and during diastole in the Rasa $1^{f l / f l} U b^{\text {ertzcre }}$ vessel. (B) Shown is the mean pump limit plus SEM for vessels from littermate Rasa ${ }^{f l / f l}(n=4)$ and Rasa $7^{f l / f l} U b^{\text {ertzcre }}$ mice $(n=5)$ in pump-function tests. The pump limit is defined as the adverse pressure $\left(\mathrm{P}_{\text {out }}-\mathrm{P}_{\text {in }}\right)$ at pump failure. ${ }^{* *} P<0.0025$, Student's 2 -sample $t$ test.

were also observed in mice in which the Rasa1 gene was disrupted specifically within LV endothelial cells (LECs), showing that they result from loss of RASA1 within this cell type (11). Development of LV hyperplasia was attributed to dysregulated signaling through VEGFR3 in LECs. However, whether any of the LV abnormalities in these mice result from dysregulated Ras activation or perturbations in other signaling pathways was not addressed. In addition, the basis of LV leakage defects in induced RASA1-deficient mice was not determined. These are important questions, since answers are likely to provide insights into the pathogenesis of LV abnormalities in patients with CM-AVM as well as suggest possible means of treatment.

In previous near-infrared fluorescence lymphatic imaging (NIRFLI) studies of live induced RASA1-deficient mice and humans with RASA1 mutations, we noticed back-flow of dye at injection sites suggestive of an LV valve defect that could account for leakage $(4,11)$. Collecting LVs contain intraluminal semilunar valves that are essential for propulsive lymph flow in these contractile vessels $(13,14)$. LV valvulogenesis is initiated in late gestation and proceeds through 4 distinct steps (15-20). In the first step, oscillatory shear stress contributes to the formation of rings of valve-forming cells with increased expression of prospero homeobox 1 (PROX1), forkhead box C2 (FOXC2), and GATA binding protein 2 (GATA2) transcription factors, which drive subsequent steps of valve formation. In the second step, known as condensation, the rings compress and valve-forming cells orient $90^{\circ}$ toward the vessel lumen. This is accompanied by the nuclear mobilization of the NFATc1 transcription factor that is dependent upon the GAP junction protein connexin 37 (CX37). In the third step, valve-forming cells protrude into the vessel lumen, elongate in the direction of lymph flow, and produce extracellular matrix (ECM) proteins (e.g., laminin $\alpha 5$, fibronectin-EIIIA, collagen IV, and EMILIN1), which form the core of the valve leaflet. Elongation is mediated by integrin $\alpha-9$, which anchors the valve-forming cells to the ECM. In the fourth step, additional ECM deposition results in the thickening of leaflets and valve maturation. Mice that 
A

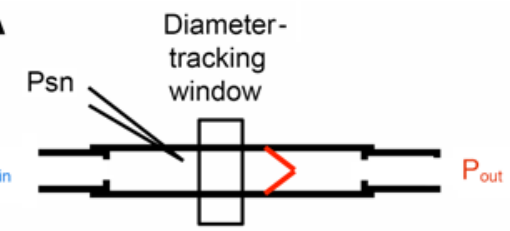

B
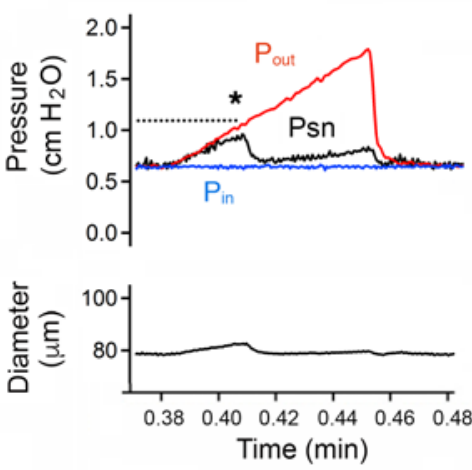

Rasa1 ${ }^{f l f l} U b^{\text {ert2cre }}(9 \mathrm{wk})$
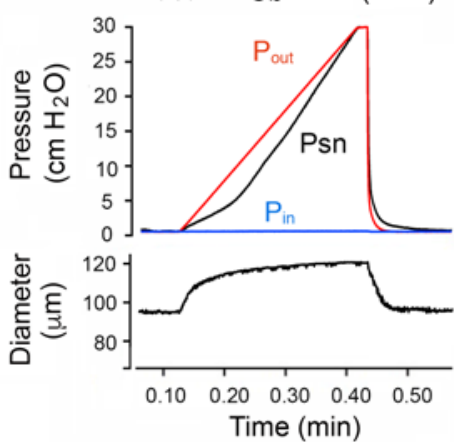

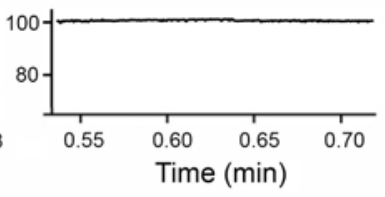

$\operatorname{Rasa1}^{f / / f l}(9 \mathrm{wk})$

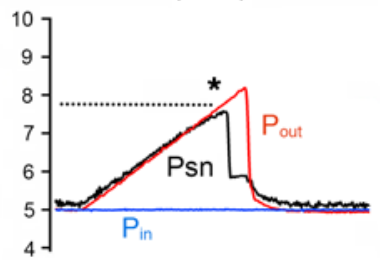

Rasa ${ }^{\mathrm{flfl}} \mathrm{Ub} \mathrm{b}^{\text {ert2cre }}$ (9 wk)
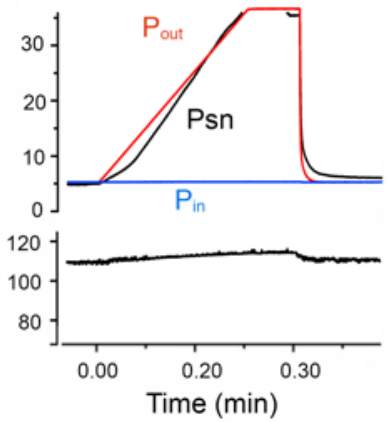

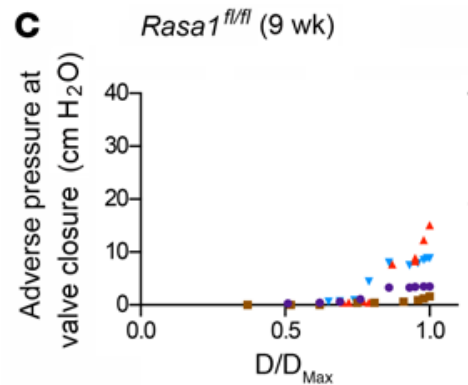

Rasa ${ }^{f l / f l} U b^{\text {ert2cre }}(9 \mathrm{wk})$

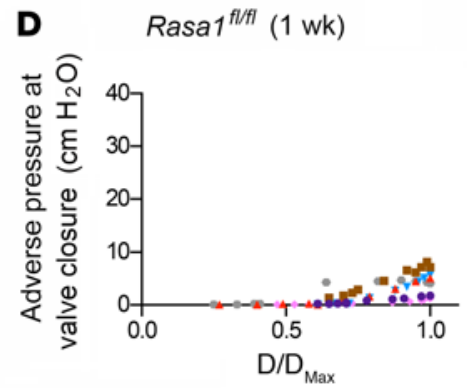

Rasa1 $^{f l f l} U b^{\text {ert2cre }}(1 \mathrm{wk})$
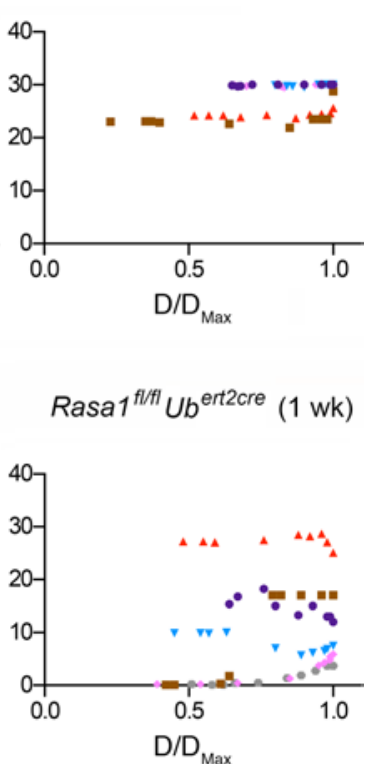

Figure 2. Valves in induced RASA1-deficient LVs fail to close in valve-closure tests. (A) Popliteal LVs, trimmed to contain a single valve, were cannulated with pipettes to allow control of upstream $\left(P_{\text {in }}\right)$ and downstream $\left(P_{\text {out }}\right)$ pressure. Assays were conducted in calcium-free medium to prevent vessel contraction. $P_{\text {in }}$ was held constant, and $P_{\text {out }}$ was increased until valve closure, assessed by a drop in upstream pressure as measured with the use of a servo-null micropipette (Psn) and by a decrease in vessel diameter. The position of the diameter-tracking window is shown. The amount of adverse pressure ( $P_{\text {out }}-$ $P_{\text {in }}$ ) required for valve closure over a range of $P_{\text {in }}$ and initial vessel diameters was determined. (B) Examples of traces from valve-closure tests performed

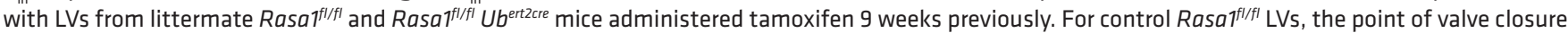
is indicated with an asterisk. Adverse pressure required for valve closure is represented by the difference between the dotted and $P_{\text {in }}$ lines. Note that increased amounts of adverse pressure are required for valve closure at increased $P_{\text {in }}$ and initial vessel diameter. Note also apparent failed valve closure in the Rasa1 ${ }^{f l f l} U_{b^{e r t 2 c r e}}$ LVs up to maximum tested adverse pressures of $30 \mathrm{~cm} \mathrm{H}_{2} \mathrm{O}$ at either tested $\mathrm{P}_{\text {in. }}$. (C) Plots of adverse pressure required for valve closure at different vessel diameters (D) represented as $D / D_{\text {max }}$, where $D_{\text {max }}$ is defined as vessel diameter at a maximum tested $P_{\text {in }}$ of $10 \mathrm{~cm} \mathrm{H}_{2} \mathrm{O}$. Individual valves from littermate $\operatorname{Rasa}^{f l f l}(n=4)$ and $\operatorname{Rasa}^{f / f l} U b^{\text {ertzcre }}(n=5)$ mice treated with tamoxifen 9 weeks previously are represented by the same colored symbols. (D) Plots of adverse pressure required for valve closure over a range of $D / D$ of $L$ s from littermate $R a s a 1^{f / f I}(n=6)$ and $R a s a 1^{f l / f l} U b^{\text {ert } 2 \text { cre }}(n=6)$ mice treated with tamoxifen 1 week previously.

are deficient in genes that are expressed in LV valves illustrate the importance of the respective proteins at different steps of valve formation. For example, FOXC2-deficient mice fail to develop valves at all (21). In contrast, CX37-deficient, CNB1-deficient (CNB1, a calcineurin subunit, is required for NFAT signaling), and integrin $\alpha$-9-deficient mice develop valves that arrest at stages 1 , 2 , and 3 , respectively $(15,16,22)$. Often, the same genes involved in the development of $\mathrm{LV}$ valves are also required for valve maintenance in adults, e.g., FOXC2 and GATA2 (20, 23). In contrast, other genes appear to be required for valve development but not maintenance, e.g., integrin $\alpha-9(15,24)$.
In this study, we used an inducible RASA1-deficient mouse model to examine whether RASA1 is necessary for the normal functioning of adult LV valves. In addition, we used an inducible Rasa1 ${ }^{R 780 Q}$ mouse model to examine whether lymphatic phenotypes that develop in induced RASA1-deficient mice, including potential valve dysfunction, result from loss of RASA1 catalytic activity directed toward Ras or to loss of a noncatalytic function of RASA1. Whether RASA1 catalytic activity is required for lymphatic vasculogenesis was also examined in these studies. We report an essential function for RASA1 in valve maintenance and development that is partly dependent or completely dependent upon 


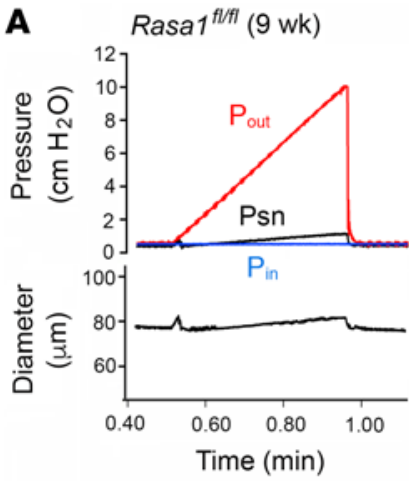

B
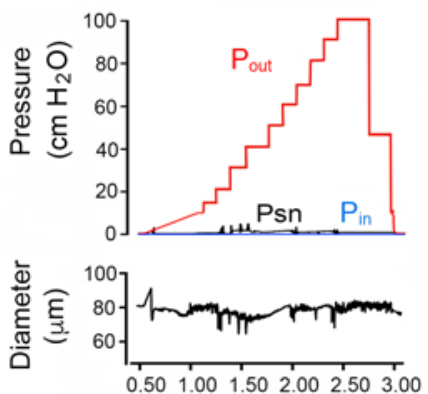

Time (min)

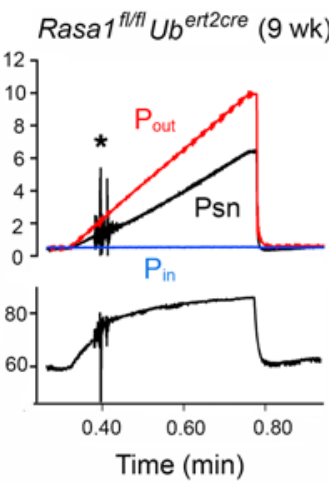

$\operatorname{Rasa1}^{f l f l} U b^{\text {ert2cre }}(9 \mathrm{wk})$
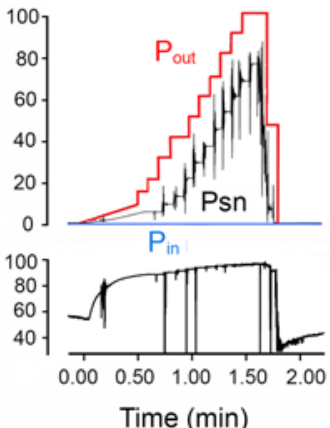
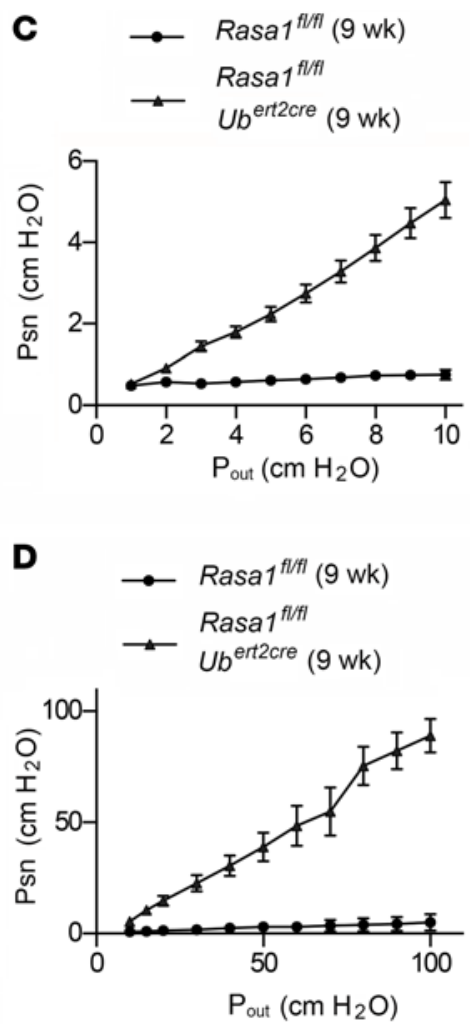
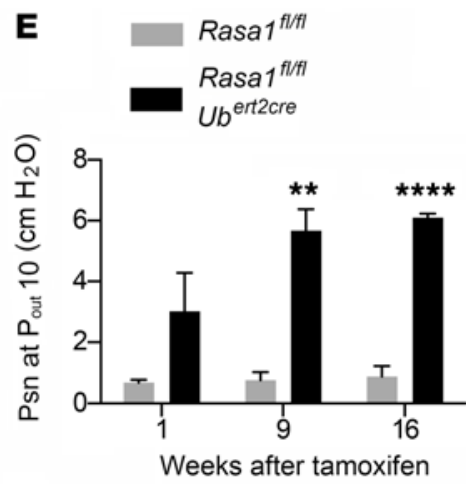

$\mathbf{F}$

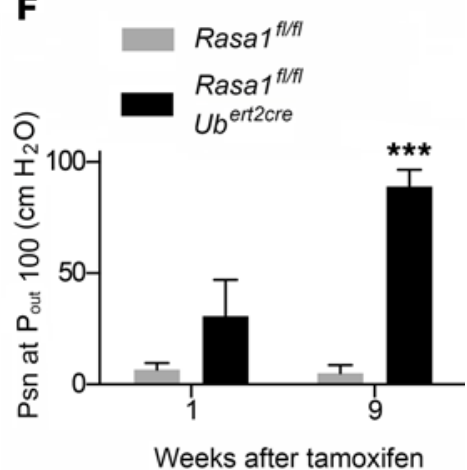

Figure 3. Induced RASA1-deficient valves are unable to prevent back-leak. (A and B) Example of traces of low-pressure (A) and high-pressure (B) backleak tests performed with LVs from littermate Rasa $1^{f / f l}$ and $R a s a f^{f / f l} U b^{\text {ertzcre }}$ mice administered tamoxifen 9 weeks previously. Experimental setup was as in valve-closure tests (Figure $2 \mathrm{~A}$ ). $\mathrm{P}_{\text {in }}$ was kept constant at $0.5 \mathrm{~cm} \mathrm{H} \mathrm{H}_{2} \mathrm{O}$, and $\mathrm{P}_{\text {out }}$ was increased from 0.5 to $10 \mathrm{~cm} \mathrm{H}_{2} \mathrm{O}$ in low-pressure back-leak tests or in $10 \mathrm{~cm} \mathrm{H}_{2} \mathrm{O}$ increments to $100 \mathrm{~cm} \mathrm{H}_{2} \mathrm{O}$ in high-pressure back-leak tests. Back-leak of the increased $\mathrm{P}_{\text {out }}$ to the upstream vessel lumen was measured using the Psn micropipette. In low-pressure back-leak tests, closure of RASA1-deficient valves was encouraged at the beginning of the $P_{\text {out }}$ ramp by tapping to introduce spikes in intraluminal pressure (asterisk). (C and D) Mean Psn \pm SEM at different $P_{\text {out }}$ in low-pressure (C) and high-pressure (D) back-leak tests performed upon valves from littermate $\operatorname{Rasa}^{f l / f I}(n=3)$ and Rasa ${ }^{f / f l} U b^{\text {ertzcre }}(n=7)$ mice administered tamoxifen 9 weeks previously. (E and F) Mean Psn \pm SEM at $P_{\text {out }} 10 \mathrm{~cm} \mathrm{H}_{2} \mathrm{O}$ in low-pressure back-leak tests $(\mathbf{E})$ and $\mathrm{P}_{\text {out }} 100 \mathrm{~cm} \mathrm{H}_{2} \mathrm{O}$ in high-pressure back-leak tests (F) performed upon valves from littermate $R a s a f^{f / f l}$ and Rasa $a^{f / / f l} U b^{\text {ertzcre }}$ mice administered tamoxifen at the indicated number of weeks beforehand ( $n=6$ of each genotype at 1 and 16 weeks; $n=3$ Rasa $^{f / f f l}$ and $n=7$ Rasa $7^{f l / f l} U^{\text {ertzcre }}$ mice at 9 weeks after tamoxifen treatment). See also Supplemental Videos 1 and 2, which show valve behavior in low-pressure back-leak tests conducted with $R a s a 1^{f / f l}$ and $R a s a f^{f l / f l} U b^{\text {ertzcre }}$ vessels, respectively, 1 week after tamoxifen treatment. ${ }^{* *} P<0.0025$; ${ }^{* *} P<0.0005 ;{ }^{* * *} P<0.0001$, Student's 2-sample $t$ test.

RASA1 catalytic activity in these respective roles. In valve development, we further show that a role for RASA1 is explained by an essential function in the survival of LECs in valve leaflets.

\section{Results}

Induced RASA1-deficient LVs are ineffective as pumps. The majority of assays of $L V$ function ex vivo were performed upon afferent popliteal collecting LVs. To induce loss of RASA1 protein in vessels, we used mice carrying conditional floxed Rasa1 alleles (Rasa $\left.1^{7 / f f}\right)$ and ubiquitin-3 promoter-driven, tamoxifen-inducible Cre $\left(U b b 3-C r e E R^{T 2}\right.$, referred to here as $\left.U b^{\text {ertzere }}\right)$. Rasa ${ }^{A / f l} U b^{\text {ertzere }}$ mice were administered tamoxifen at 2 months of age. Littermate Rasaft/fl mice were also administered tamoxifen at the same time and served as controls. We first examined contractile activity of vessels (Supplemental Figure 1A; supplemental material available online with this article; https:/doi. org/10.1172/JCI89607DS1). These assays were conducted in medium containing calcium to permit spontaneous vessel contraction. Trimmed vessels that contained 2 valves were cannulated at open ends to allow manipulation of intraluminal pressure upstream $\left(\mathrm{P}_{\text {in }}\right)$ of valve 1 and downstream $\left(\mathrm{P}_{\text {out }}\right)$ of valve 2. $\mathrm{P}_{\text {in }}$ and $\mathrm{P}_{\text {out }}$ were changed in parallel, and the amplitude and frequency of contractions were determined by measurement of vessel diameter between the 2 valves. In Rasa $1^{7 / f}$ control vessels, as intraluminal pressure was increased, the frequency of contractions increased and contraction amplitude decreased, as expected (Supplemental Figure 1, B and C). Moreover, in vessels from Rasa ${ }^{7 / f / A} U b^{\text {ertzere }}$ mice (treated with tamoxifen 9 weeks previously), similar changes in contraction frequency and amplitude were noted in response to increased intraluminal pressure (Supplemental Figure 1, B and C). Ejection fraction and fractional pump flow rate were also comparable between the 2 groups of mice (Supplemental Figure 1C). These findings indicate that the contractile function of collecting LVs is not affected by the loss of RASA1.

We next compared the ability of control and RASA1-deficient LVs to pump fluid against an adverse pressure gradient. Efficient pumping requires normal valve function as well as robust muscle contraction (25). Experiments were conducted similarly to contraction assays, except that only $\mathrm{P}_{\text {out }}$ was increased while $\mathrm{P}_{\text {in }}$ was held at a constant low level of $0.5 \mathrm{~cm} \mathrm{H}_{2} \mathrm{O}$. Video recordings of the down- 
A

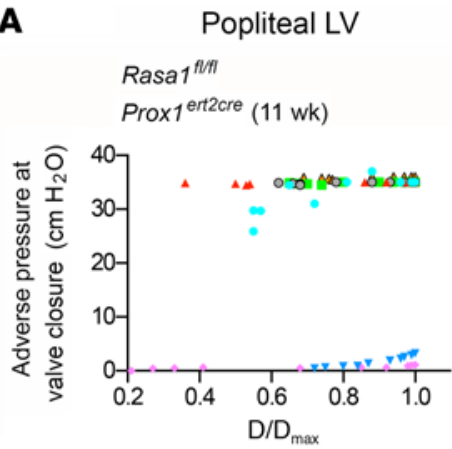

D
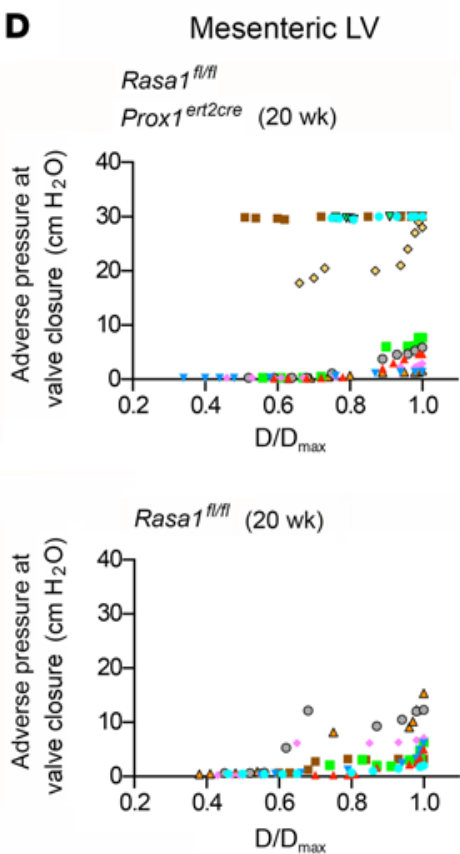

B
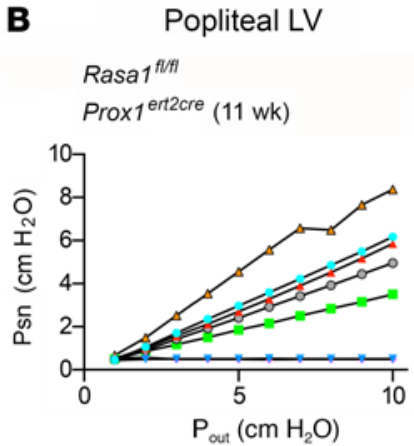

E
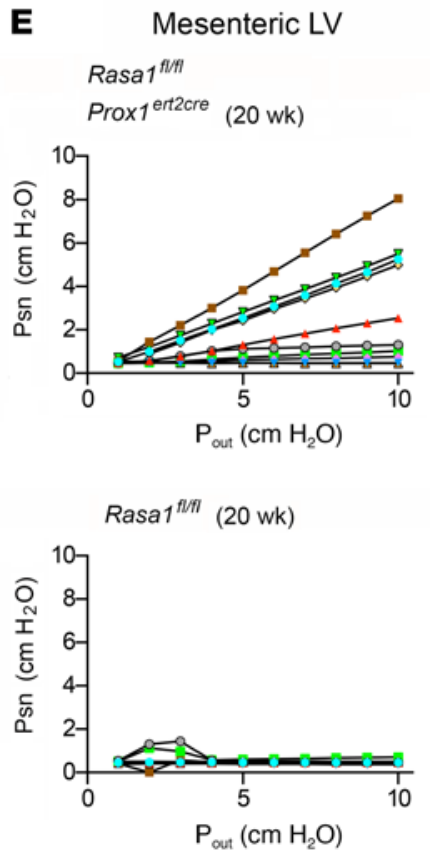

C

Popliteal LV

Rasa1 flum

Prox $1^{\text {ert2cre }}$ (11 wk)

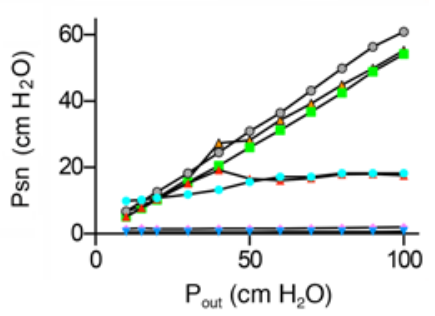

$\mathbf{F}$

Mesenteric LV

Rasa1 $1^{\text {flfl }}$

Prox1 ${ }^{\text {ert2cre }}$ (20 wk)
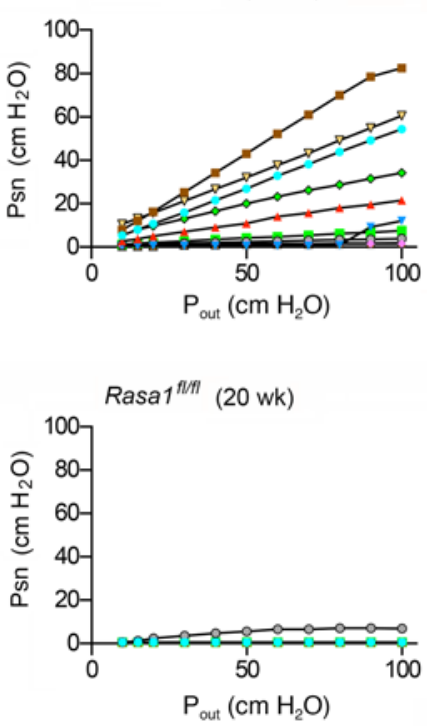

Figure 4. Specific induced loss of RASA1 within LECs results in dysfunction of popliteal and mesenteric LV valves. LV valve function tests were conducted with popliteal LV valves from Rasa $7^{f l f l}$ Prox ${ }^{\text {ertzcre }}$ mice administered tamoxifen 11 weeks previously $(\mathbf{A}-\mathbf{C})(n=7)$ or mesenteric LV valves from littermate Rasa $7^{f l / f l}$ and

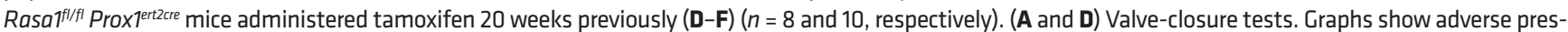
sure required for valve closure versus $D / D_{\text {max }}$. Each valve is represented by a different colored symbol. (B and $\mathbf{E}$ ) Graphs show Psn as a function of $P_{\text {out }}$ in low-pressure back-leak tests. ( $\mathbf{C}$ and $\mathbf{F}$ ) Graphs show Psn as a function of $P_{\text {out }}$ in high-pressure back-leak tests. The same colored symbols are used for the same valves in

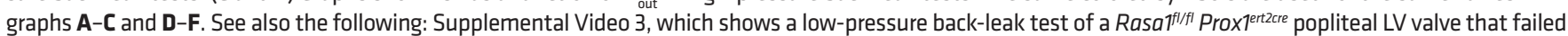
to close and leaked (gray circles in A-C); Supplemental Video 4, which shows a high-pressure back-leak test of a control Rasa fl/fl popliteal LV valve; Supplemental Video 5, which shows a high-pressure back-leak test of a Rasa fl/ffl Prox $7^{\text {ertzcre }}$ popliteal LV valve that closed at a $\mathrm{P}_{\text {out }}$ of $50 \mathrm{~cm} \mathrm{H}_{2} \mathrm{O}$ and prevented further back-leak thereafter (red triangles in A-C); Supplemental Video 6, which shows a low-pressure back leak test of a Rasa ${ }^{\text {fllfll }}$ mesenteric LV valve; Supplemental Video 7, which

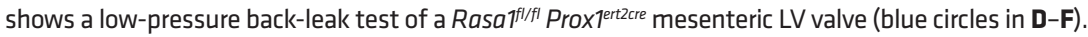

stream valve permitted a determination of the pump limit, defined as the value of adverse pressure $\left(\mathrm{P}_{\text {out }}-\mathrm{P}_{\text {in }}\right)$ at which the downstream valve locks into a closed or open position (Figure 1, A and B). LVs from control Rasa flfl $^{\text {fl }}$ mice behaved as expected in these assays and were able to effectively pump fluid against modest adverse pressure gradients $\left(2-4.8 \mathrm{~cm} \mathrm{H}_{2} \mathrm{O}\right)$. In contrast, LVs from Rasa $1^{\mathrm{t} / \mathrm{fl}}$ $U b^{\text {ertzcre }}$ mice treated with tamoxifen 9 weeks previously were ineffective as pumps. Whereas in control vessels, the downstream valve was mostly in a closed position throughout the $\mathrm{P}_{\text {out }}$ ramp, in the RASA1-deficient vessels, the downstream valve was mostly in an open position (Figure 1A). Correlation of vessel diameter with valve position provided further information upon the basis of the impaired pumping function of the RASA1-deficient vessels. In con- trol vessels, valves opened during systole and closed during diastole under conditions of adverse pressure up to the pump limit. In contrast, in RASA1-deficient vessels, the downstream valve reopened inappropriately during the diastolic phase of the vessel contraction cycle (Figure 1A). Since contraction frequency and amplitude were not altered (Supplemental Figure 1), these findings suggested that the RASA1-deficient vessels have a primary valve defect that would account for the impaired pumping function.

Induced RASA1-deficient LV valves fail to close properly in response to adverse intraluminal pressure. To examine valve function directly, we performed valve-closure tests upon control and RASA1-deficient vessels. For these experiments, vessels from

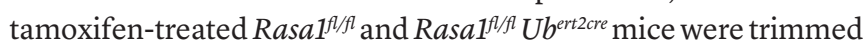


A Leaflet length

Vessel diameter

Sinus diameter

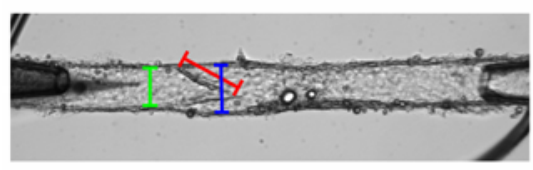

C

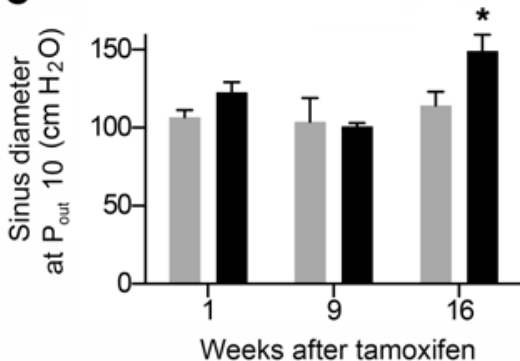

E
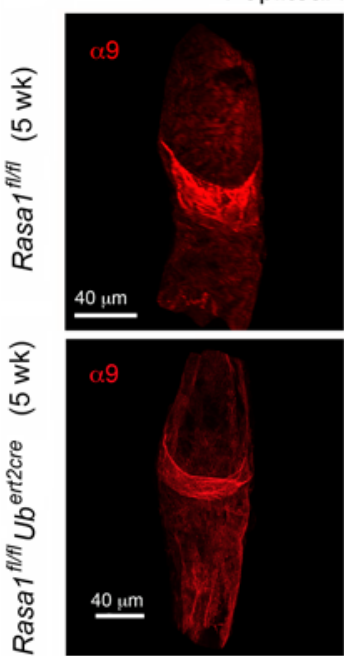

$\mathbf{F}$

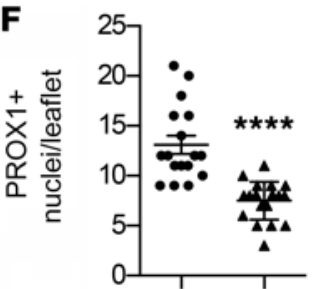

B

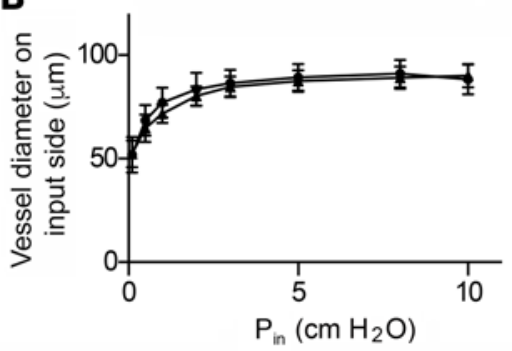

D

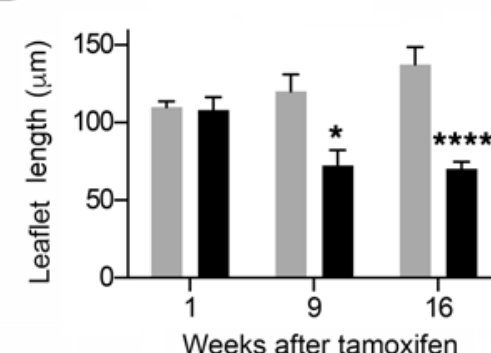

$\rightarrow \operatorname{Rasa1}^{\mathrm{flut}}(9 \mathrm{wk})$

Rasa $1^{\text {fllf }}$

$U b^{\text {ert2cre }}(9 \mathrm{wk})$
Rasa $1^{f / f i}$
Rasa $1^{\text {fl/fi}}$
Ub $^{\text {ert2cre }}$
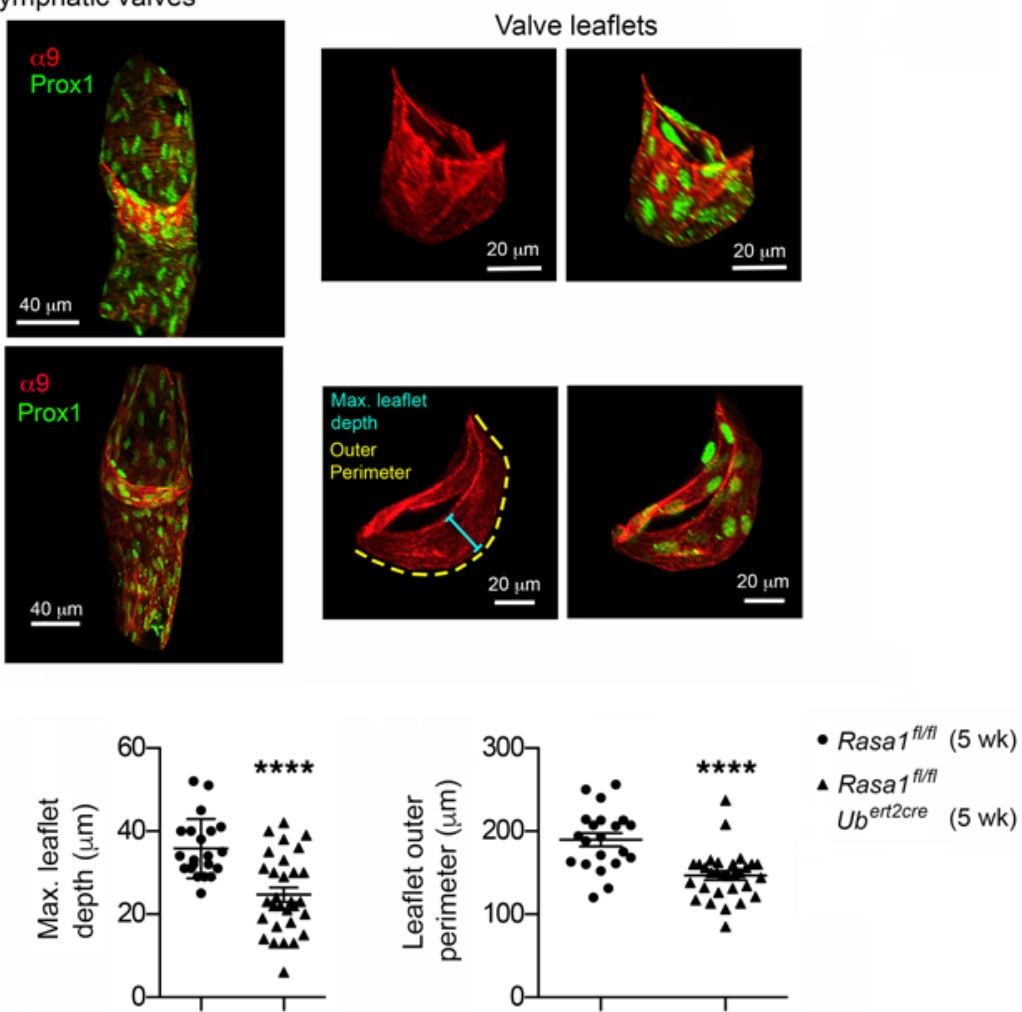

Figure 5. LV valve leaflet atrophy associated with reduced numbers of leaflet PROX1+ LECs in induced RASA1-deficient mice. All analyses were performed with popliteal LV valves. (A) Still image of popliteal LV valve from a back-leak experiment indicating parameters measured for B-D. (B) Mean vessel diameter \pm SEM at different upstream pressures $\left(P_{\text {in }}\right)$ of $L V$ s from Rasa $7^{f l / f l}(n=4)$ and Rasa $1^{f l / f l} U b^{\text {ertzcre }}(n=7)$ mice treated with tamoxifen 9 weeks previously. (C) Mean sinus diameter $+\mathrm{SEM}$ at $\mathrm{P}_{\text {out }} 10 \mathrm{~cm} \mathrm{H} \mathrm{H}_{2} \mathrm{O}$ of LVs from littermate Rasa $1^{f l / f l}$ and Rasa ${ }^{f l / f l} U b^{\text {ertzcre }}$ mice treated with tamoxifen 1,9 , and 16 weeks previously ( $n=6$ of each genotype at 1 and 16 weeks; $n=3$ Rasa $1^{f l / f l}$ and $n=7$ Rasa ${ }^{f l / f l} U b^{\text {ertzcre }}$ mice at 9 weeks after tamoxifen treatment). (D) Mean leaflet length + SEM of LVs from littermate Rasaf $f^{\prime / f l}$ and Rasa $f^{f / f l} U b^{\text {ertzcre }}$ mice treated with tamoxifen 1 , 9 , and 16 weeks previously ( $n=12$ of each genotype at 1 and 16 weeks; $n=6$ Rasa $1^{f l / f l}$ and $n=13$ Rasa $1^{f l / f l} U b^{\text {ertzcre }}$ at 9 weeks after tamoxifen treatment). (E) Confocal microscopy images of popliteal LVs from littermate Rasa $1^{f l / f l}$ and Rasaffl/fl $U b^{\text {ertzcre }}$ mice administered tamoxifen 5 weeks beforehand. Vessels were stained with integrin $\alpha-9$ and PROX1 antibodies to highlight valve leaflets. Larger images at left show whole-valve regions. Smaller images at right show valve leaflets only from the same valves. One valve leaflet image is marked to indicate maximum leaflet depth, and outer perimeter is shown in F. (F) Graphs show maximum leaflet depth, leaflet outer perimeter, and number of PROX1+ cells per leaflet for different LV valve leaflets from Rasa $1^{f / f l}$ and Rasa $f^{f / f l} U b^{\text {ertzcre }}$ mice administered tamoxifen 5 weeks beforehand. Mean + SEM are indicated. ${ }^{*} P<0.05$;

****P<0.0001, Student's 2-sample $t$ test. 
further so that they contained a single valve before they were recannulated at both ends (Figure 2A). Assays were conducted in calcium-free media to prevent lymphatic muscle contraction. $\mathrm{P}_{\text {out }}$ was increased, and the value of $\mathrm{P}_{\text {out }}$ required to close valves was determined at different values of $\mathrm{P}_{\text {in }}$ and, consequently, upstream vessel diameters. The point at which valves closed was assessed with the use of a servo-null micropipette (Psn) inserted through the vessel wall into the upstream vessel lumen to detect decreases in upstream intraluminal pressure that would be expected upon valve closure. In addition, upstream vessel diameter was recorded to provide confirmation of valve closure.

Valves from control Rasa1 $1^{f / f l}$ mice behaved as expected in closure tests. As reported previously for rat LV valves, the amount of adverse pressure $\left(\mathrm{P}_{\text {out }}-\mathrm{P}_{\text {in }}\right)$ required to close valves increased with increased upstream vessel diameter (Figure 2, B and C). However, even at maximum diameter, all control valves closed with moderate adverse pressures that did not exceed $15 \mathrm{~cm} \mathrm{H}_{2} \mathrm{O}$. In contrast, all examined valves from Rasa1 $^{f / f l} U^{\text {ert2cre }}$ mice treated with tamoxifen 9 weeks earlier failed to close at any tested upstream vessel diameter up to maximum tested adverse pressures in the range of $20-30 \mathrm{~cm} \mathrm{H}_{2} \mathrm{O}$ (Figure 2, B and C). Thus, RASA1-deficient LV valves are unable to close properly in response to adverse intraluminal pressure.

To determine how soon the valve closure defect manifests after loss of RASA1, we also examined vessels from Rasa1 $1^{f / f l}$ and Rasa1 ${ }^{f l / f l} U b^{\text {ert2cre }}$ mice that had been treated with tamoxifen 1 week earlier (Figure 2D). All examined valves from the Rasal ${ }^{f / f l}$ mice behaved normally. In contrast, abnormal valve closure was evident in 4 out of 6 tested valves from Rasa1 ${ }^{f / f l} U b^{\text {ert } 2 \text { cre }}$ mice. One valve failed to close at any initial vessel diameter, 2 required abnormally high adverse pressures for closure at small vessel diameters, and 1 required higher than normal adverse pressures for closure at large vessel diameters. The other 2 examined valves behaved similarly to controls (Figure 2D). Therefore, abnormalities of valve closure can be detected at an early time point after RASA1 loss.

Back-leak across induced RASA1-deficient LVvalves. We attempted to measure the extent to which closed valves in RASA1-deficient LVs could resist back-leak of elevated intraluminal pressure downstream of the valve. As for valve-closure tests, back-leak assays were performed with vessels that contained a single valve in calcium-free medium. In low-pressure back-leak tests, $\mathrm{P}_{\text {in }}$ was kept at a constant low level of $0.5 \mathrm{~cm} \mathrm{H}_{2} \mathrm{O}$ and $\mathrm{P}_{\text {out }}$ was elevated over a physiological range from 0.5 to $10 \mathrm{~cm} \mathrm{H}_{2} \mathrm{O}$. Psn recordings provided an indication of the extent of back-leak (Figure 3A). As in closure tests, valves from control Rasa ${ }^{f / f l}$ mice closed spontaneously in response to small amounts of adverse pressure and, furthermore, resisted transfer of pressure to the upstream vessel lumen throughout the entire $\mathrm{P}_{\text {out }}$ range (Figure 3, A, C, and E).

Since RASA1-deficient valves failed to close properly in valve-closure tests, initial valve closure in low-pressure back-leak tests was encouraged by tapping of the vessel line to introduce spikes of intraluminal pressure (Figure 3A). Nonetheless, valves from Rasal ${ }^{l / f l} U b^{\text {ertzcre }}$ mice treated with tamoxifen 9 weeks previously failed to prevent transfer of pressure to the upstream lumen throughout the $\mathrm{P}_{\text {out }}$ range (Figure 3, A and C). Back-leak across valves from Rasa1 ${ }^{f / f l} U b^{\text {ert2cre }}$ mice in low-pressure back-leak tests was apparent as soon as 1 week for some valves (see later) and persisted until at least 16 weeks after tamoxifen treatment (Figure 3E).
In high-pressure back-leak tests, we measured valve back-leak under conditions of supraphysiological downstream pressure up to $100 \mathrm{~cm} \mathrm{H}_{2} \mathrm{O}$ (Figure 3B). All tested valves from Rasal ${ }^{t / f l}$ mice were able to resist increased downstream pressure throughout the $\mathrm{P}_{\text {out }}$ range in these tests (Figure 3, B and D). In contrast, valves from Rasa1 ${ }^{f / f l} U b^{\text {ert2cre }}$ mice treated with tamoxifen 9 weeks earlier were unable to resist these pressure increases (Figure 3, B, D, and F). Subsequent analysis of video recordings of valves in low- and high-pressure back-leak tests revealed that valves from Rasa1 ${ }^{f / f l}$ $U b^{\text {ertzcre }}$ mice failed to close properly in both types of tests despite the line tapping or very high downstream pressures, respectively (Supplemental Videos 1 and 2 and data not shown). Failure of valve closure, therefore, accounts for the back-leak.

Specific induced disruption of the Rasa1 gene in LECs results in impaired $L V$ valve function. To determine whether loss of RASA1 in LECs was sufficient for the development of LV valve dysfunction, we examined popliteal LVs from Rasa1 ${ }^{\text {fl/fl }}$ Prox $^{\text {ert } 2 \text { cre }}$, which express a lymphatic endothelial cell-specific tamoxifen-inducible Cre. Eleven weeks after tamoxifen administration to adult mice, popliteal LVs were tested in valve closure assays and low- and high-pressure back-leak tests (Figure $4, \mathrm{~A}-\mathrm{C}$ ). In valve-closure tests, 4 out of 7 tested valves failed to close at any tested vessel diameter and adverse pressure and 1 closed only at low vessel diameter with high adverse pressure (Figure 4A). Two other valves closed normally (Figure 4A). All of the 5 valves that were unable to close properly in closure tests were unable to resist back-leak in low- and high-pressure back-leak tests (Figure 4, B and C). Video analysis of valves in low-pressure back-leak tests confirmed that, for each of these 5 valves, valve closure never occurred, thereby accounting for back-leak (Supplemental Video 3). However, for 2 of these valves, valve closure did occur at a $\mathrm{P}_{\text {out }}$ of $50 \mathrm{~cm} \mathrm{H}_{2} \mathrm{O}$ in high-pressure back-leak tests, which prevented further elevations in upstream pressure (Figure $4 \mathrm{C}$ and Supplemental Videos 4 and $5)$. Both of the other 2 valves that closed normally in valve-closure tests also closed normally in low- and high-pressure back-leak tests and resisted back-leak throughout the $\mathrm{P}_{\text {out }}$ ramps in those tests (Figure 4, B and C). In summary, the majority of valves from tamoxifen-treated Rasa1 $1^{f / f l}$ Prox $1^{\text {ert2cre }}$ mice are dysfunctional, indicating that the valve defects observed in tamoxifen-treated Rasa1 $1^{f / f l}$ $U b^{\text {ert2cre }}$ mice result from loss of RASA1 specifically in LECs. That some valves from tamoxifen-treated Rasa1 $1^{f l / f l}$ Prox $1^{\text {ert2cre }}$ mice function normally is most likely explained by less efficient Rasa1 gene disruption using the Prox $1^{\text {ert2cre }}$ driver compared with the $U b^{\text {ert2cre }}$ driver as we reported previously (11).

Induced loss of RASA1 in LECs results in defects in the function of mesenteric as well as popliteal LV valves. We examined whether specific induced disruption of RASA1 in LECs results in valve dysfunction in other types of LVs. For this purpose, we tested mesenteric LVs from Rasa1 ${ }^{f / f l}$ and Rasa1 ${ }^{f / f l}$ Prox $1^{\text {ert2cre }}$ mice treated with tamoxifen 20 weeks previously (Figure 4, D-F). In valve-closure tests, 4 out of 10 tested mesenteric LV valves from Rasa1 ${ }^{f l / f l}$ Prox $1^{\text {ert } 2 \text { cre }}$ mice failed to close properly, whereas all 8 tested mesenteric LV valves from Rasa1 $1^{f / f l}$ mice behaved normally in these tests (Figure 4D). In back-leak tests, the same 4 dysfunctional valves from Rasa1 ${ }^{f / f l}$ Prox $1^{\text {ert2cre }}$ mice were also unable to resist back-leak. In addition, a fifth valve from Rasa1 ${ }^{f / f l}$ Prox $1^{\text {ert2cre }}$ mice, which behaved normally in valve-closure tests, showed back-leak in back-leak tests (Figure 
A

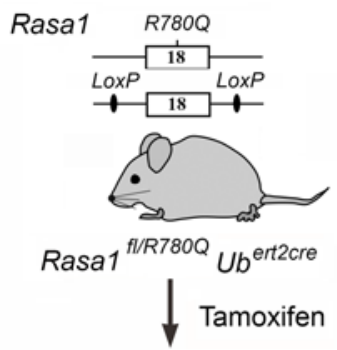

Rasa1

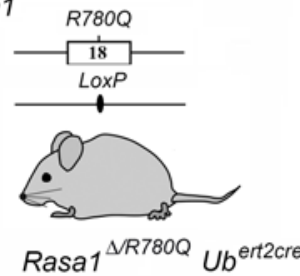

B

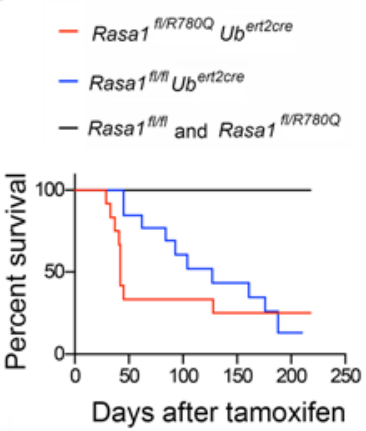

C Rasa1 ${ }^{f / f l} U b^{\text {ert2cre }}$
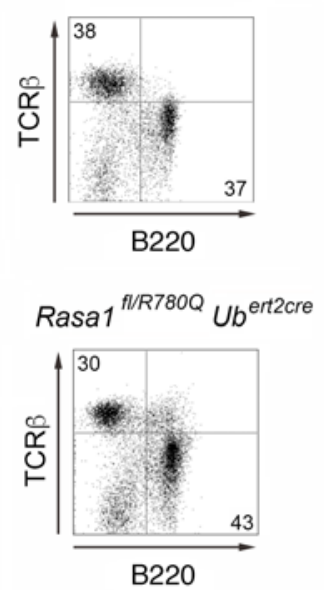

D Chest wall
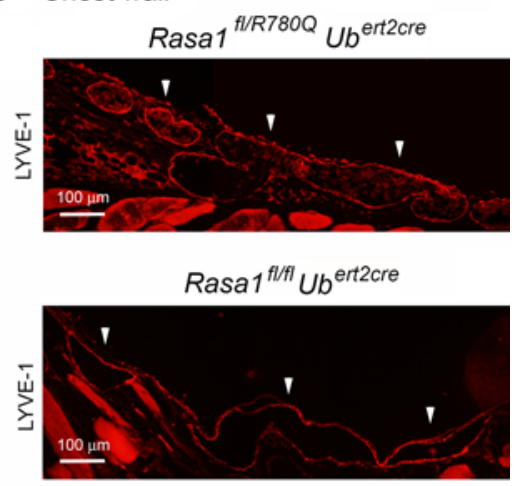
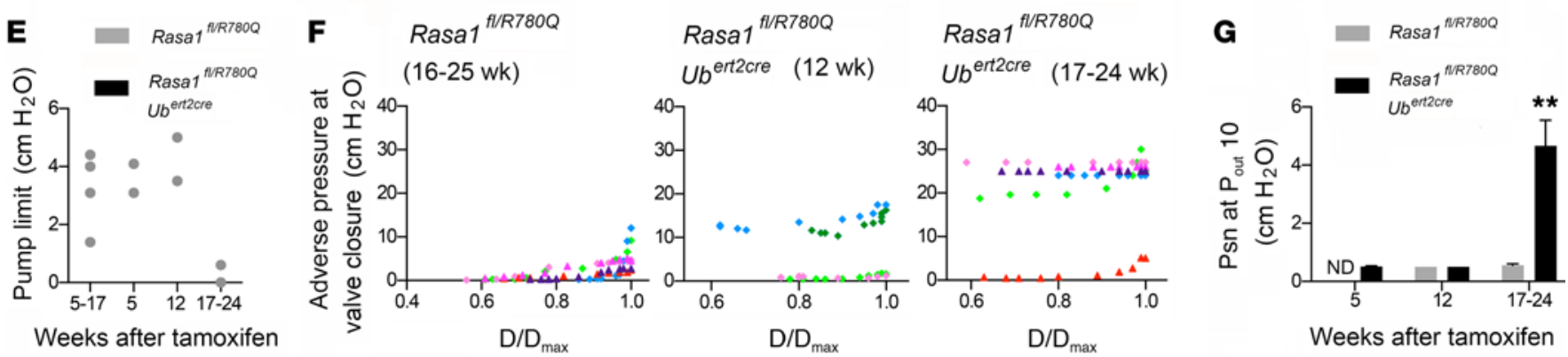

Figure 6. Adult mice that are genetically altered to express an R780Q catalytically inactive form of RASA1 alone develop chylothorax, LV hyperplasia, and LV valve dysfunction. (A) Rasa f//R7800 $U b^{\text {ertzcre }}$ mice were administered tamoxifen at 3 weeks of age to disrupt the Rasa $7^{f l}$ allele, resulting in expression

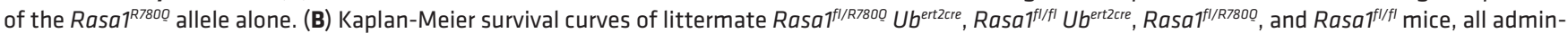
istered tamoxifen at 3 weeks of age ( $n=12$ mice of each genotype). (C) Flow cytometric analysis of pleural effusion cells from moribund tamoxifen-treated Rasaff/R7800 $U b^{\text {ertzcre }}$ and Rasaffl/fl $U b^{\text {ertzcre }}$ mice showing expression of the lymphocytic markers TCR $\beta$ (T cells) and B220 (B cells). Numbers in plots denote the percentages of live cells. Results are representative of at least 4 mice examined of each genotype. (D) LYVE-1 antibody staining of the chest wall of

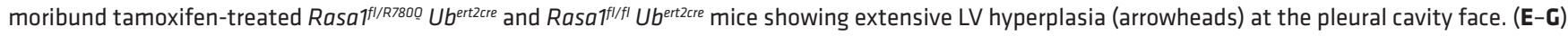
Valve function tests were performed with popliteal LVs from littermate Rasaf $f^{f / R 7800}$ and Rasa $7^{f / R 7800} U b^{\text {ertzcre }}$ mice at the indicated times after tamoxifen treatment that was administered at 2 months of age. (E) Pump-function tests. Symbols represent individual valves. (F) Valve-closure tests. Within each graph, different colored symbols represent the same valve. (C) Low-pressure back-leak tests showing mean Psn $+\mathrm{SEM}$ at a $\mathrm{P}_{\text {out }}$ of $10 \mathrm{~cm} \mathrm{H}_{2} \mathrm{O} . \mathrm{Rasa}^{f l / R 7800}$, $n=3$ and $n=6$ at 12 and 17-24 weeks, respectively; Rasa f//R7800 $U b^{\text {ertzcre }}, n=3$ at 5 and 12 weeks and $n=6$ at $17-24$ weeks. ${ }^{* *} P<0.001$, Student's 2 -sample $t$ test. See also Supplemental Videos 8 and 9, which show examples of valves from vessels of Rasa ff/R7800 $U b^{\text {ertzcre }}$ mice, 12 and 23 weeks after tamoxifen treatment respectively, in low pressure back-leak tests.

4, D-F). In contrast, all 8 tested mesenteric $\mathrm{LV}$ valves from Rasa $\mathrm{fl}^{\mathrm{fl} / \mathrm{l}}$ mice were able to resist back-leak (Figure 4, D-F). Video analysis of low-pressure back-leak tests confirmed that, for dysfunctional mesenteric LV valves from Rasa $1^{1 / f l}$ Prox $1^{\text {ertzcre }}$ mice, valve closure never occurred (Supplemental Videos 6 and 7). Thus, specific loss of RASA1 in LECs results in dysfunctional mesenteric LV valves as well as popliteal $L V$ valves.

Reduced length and cellularity of valve leaflets in LVs of induced RASA1-deficient mice. Increased vessel wall or sinus diameter or decreased valve leaflet length could each contribute to impaired $\mathrm{LV}$ valve closure. Therefore, we examined each of these parame-

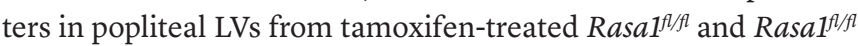
$U b^{\text {ertacre }}$ mice (Figure 5A). At 9 weeks after tamoxifen treatment, no difference in upstream vessel diameter was noted between the 2 types of mice over a range of $\mathrm{P}_{\text {in }}$ pressures from 0.5 to $10 \mathrm{~cm} \mathrm{H}_{2} \mathrm{O}$ (Figure 5B). Likewise, at 1 and 9 weeks after tamoxifen treatment, no difference in sinus diameter was noted at a $\mathrm{P}_{\text {out }}$ of $10 \mathrm{~cm} \mathrm{H}_{2} \mathrm{O}$. At
16 weeks after tamoxifen treatment, only a small increase in sinus diameter was observed in vessels from Rasa $1^{f / R /} U b^{\text {ertzere }}$ mice at the same pressure (Figure 5C). Valve leaflet measurements were made from the base of the valve sinus to the buttress of the valve leaflet at its point of attachment to the vessel wall (Figure 5A). In contrast with vessel wall and sinus diameter measurements, a significant reduction in valve leaflet length was observed at 9 weeks after

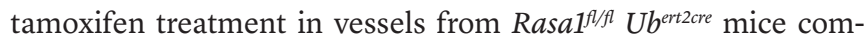
pared with Rasa $1^{f / f}$ controls and this reduction was also evident at 16 weeks (Figure 5D). These findings indicate that reduced valve leaflet length is the dominant factor responsible for impaired valve function in the absence of RASA1.

To gain further insight into the basis of $\mathrm{LV}$ valve dysfunction in the absence of RASA1, we conducted confocal microscopic imaging studies of popliteal LVs from Rasa1 ${ }^{7 / f}$ and Rasa $1^{f / f l} U b^{\text {ertzcre }}$ mice. To identify valves, vessels were costained with antibodies against PROX1 and integrin $\alpha-9$, both of which are more strongly 


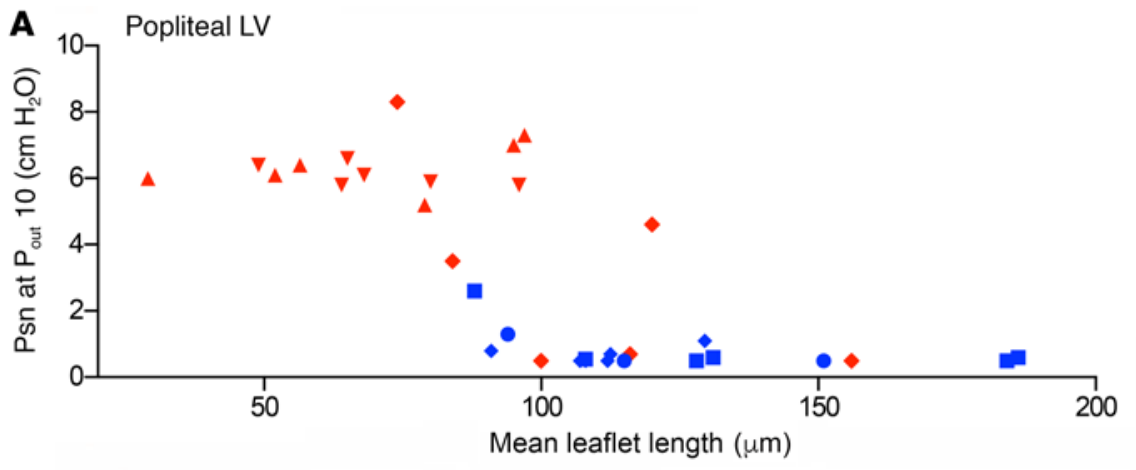

$$
\begin{aligned}
& \text { - Rasa } 1^{f / H} U b^{\text {ert2cre }} \text { (1 wk) }
\end{aligned}
$$

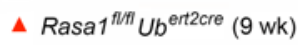

$$
\begin{aligned}
& \text { V Rasa } 1^{\text {fl/t }} U b^{\text {ert2cre (16 wk) }} \\
& \text { - Rasa1 }{ }^{f / f l} \text { (1 wk) } \\
& \text { - Rasa1 }{ }^{f l l l} \text { (9 wk) } \\
& \text { - Rasa1 }{ }^{f(l f l}(16 \mathrm{wk})
\end{aligned}
$$
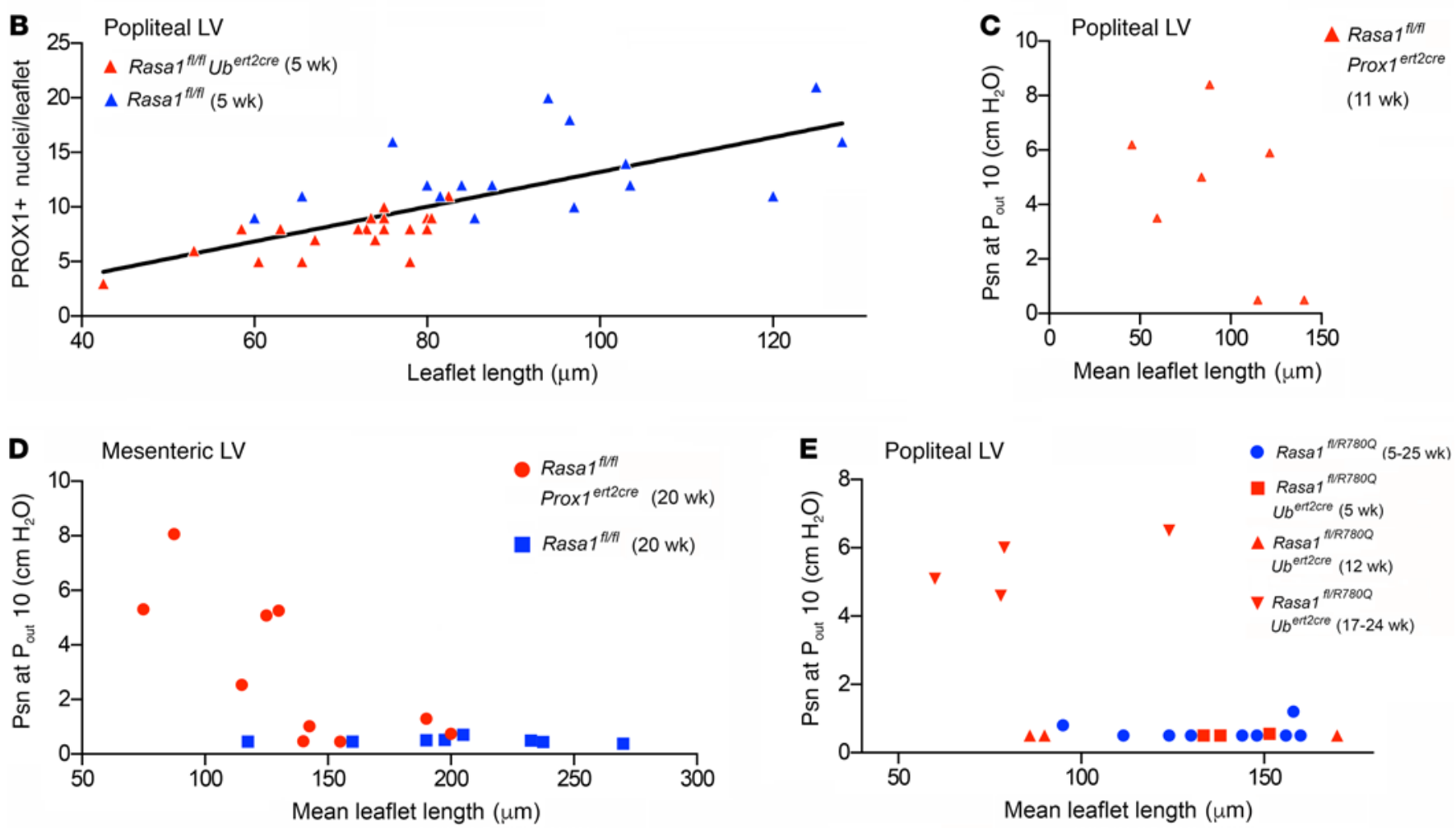

Figure 7. Reduced LV valve leaflet length in induced RASA1-deficient mice correlates with valve dysfunction. (A) Plot of mean leaflet length (Figure 5D)

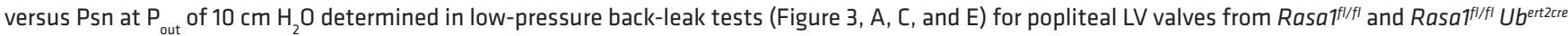
mice treated with tamoxifen 1, 9, or 16 weeks beforehand. Each symbol represents a distinct valve. (B) Plot of leaflet length versus number of PROX1+ cells per leaflet (Figure 5F) of different popliteal LV valves from Rasa ${ }^{f l / f l}$ and Rasa $7^{f / f l} \mathrm{Ub}^{\text {ertzcre }}$ mice treated with tamoxifen 5 weeks beforehand, as determined in confocal imaging experiments. A linear regression line is shown. (C) Plot of mean leaflet length versus Psn at $P_{\text {out }}$ of $10 \mathrm{~cm} \mathrm{H}_{2} \mathrm{O}$ determined in low-pressure back-leak tests of popliteal LV valves from Rasa $7^{f l / f l}$ Prox $7^{\text {ertzcre }}$ mice treated with tamoxifen 20 weeks beforehand (Figure 4B). (D) Plot of mean leaflet length versus Psn at $P_{\text {out }}$ of $10 \mathrm{~cm} \mathrm{H}_{2} \mathrm{O}$ determined in low-pressure back-leak tests of mesenteric LV valves from Rasa $1^{f / f / f l}$ and Rasa $7^{f / f f l}$ Prox ${ }^{\text {ertzcre }}$ mice treat-

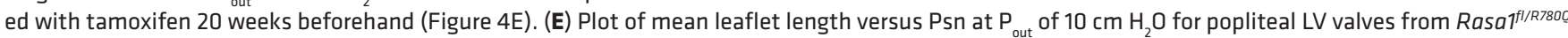
and Rasa $7^{f / R 7800} \mathrm{Ub}^{\text {ertzcre }}$ treated with tamoxifen 5-24 weeks beforehand as indicated (Figure 6C).

expressed in LECs in valve leaflets compared with LECs in the LV wall (Figure 5E) $(13,14)$. Obtained images confirmed that vessels from Rasaf ${ }^{\text {flfl }} U$ U $^{\text {ertacre }}$ mice administered tamoxifen 5 weeks earlier contained smaller valve leaflets that were marked not only by reduced leaflet outer perimeter (approximate to twice that of leaflet length defined in Figure 5A), but also reduced leaflet depth (Figure 5, E and F). Moreover, leaflets contained on average approximately $40 \%$ fewer PROX $1^{+}$LECs per leaflet (mean \pm

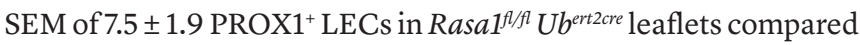

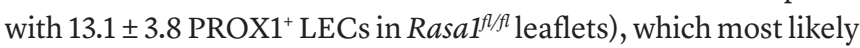
accounts for the reduced total surface area of integrin $\alpha-9$ staining
(Figure 5, E and F). In parallel with reduced cellularity, popliteal $\mathrm{LV}$ valve leaflets in tamoxifen-treated Rasal ${ }^{f / f l} U b^{\text {ertzcre }}$ and Rasal ${ }^{f / f l}$ Prox $1^{\text {ertzere }}$ mice were shown to contain reduced amounts of ECM proteins, such as collagen IV and laminin $\alpha 5$, compared with littermate Rasal ${ }^{f / f l}$ controls (Supplemental Figure 2).

Adult mice that express an $R 780 Q$ knockin mutant form of RASA1 develop chylothorax. RASA1 is a prototypical negative regulator of Ras signaling that accelerates Ras hydrolysis of GTP (7). In addition, RASA1 has also been shown to act as an adapter protein that participates in cellular signal transduction in a manner unrelated to its ability to control Ras activation (7). Theoret- 
A

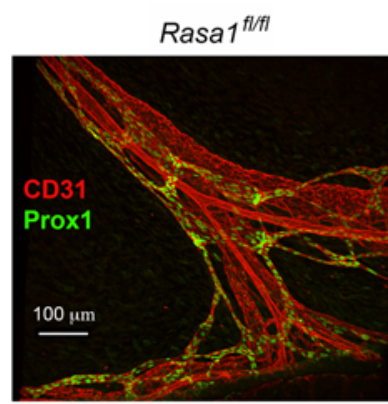

B
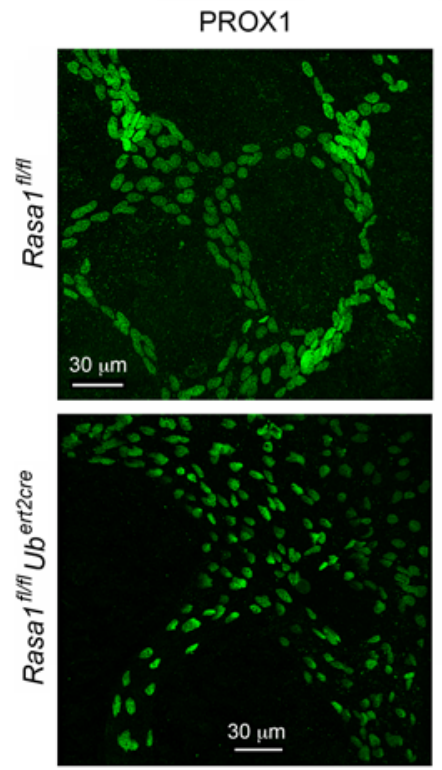

E15.5 TM-E19.5 TM analysis

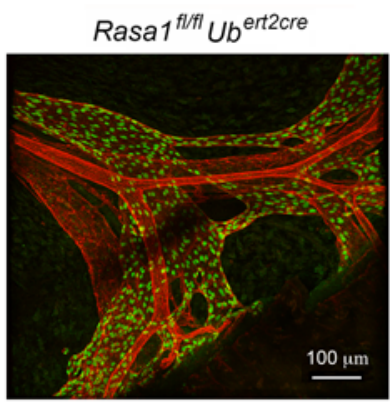

E15.5 TM-E19.5 TM analysis

$\alpha 9$
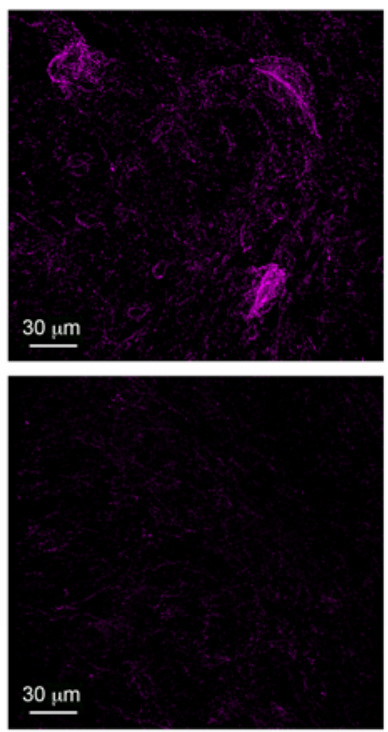

Rasa1 $^{f / R 780 Q}$

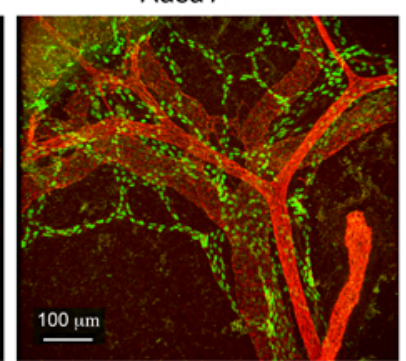

$\underline{100 \mu \mathrm{m}}$
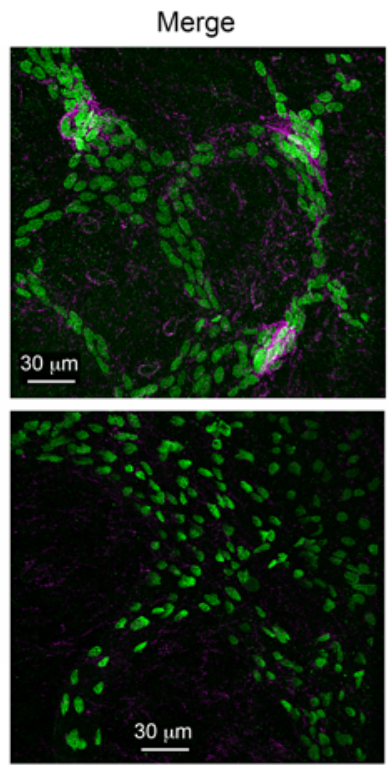

Rasa1 ${ }^{f / R 780 Q} U b^{\text {ert2cre }}$

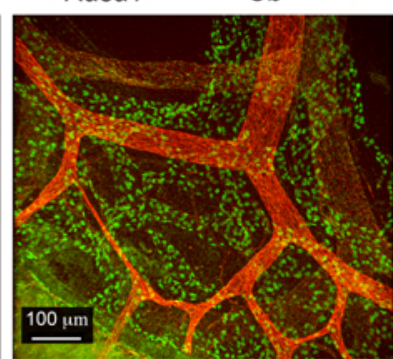

C

E15.5 TM-E19.5 TM analysis

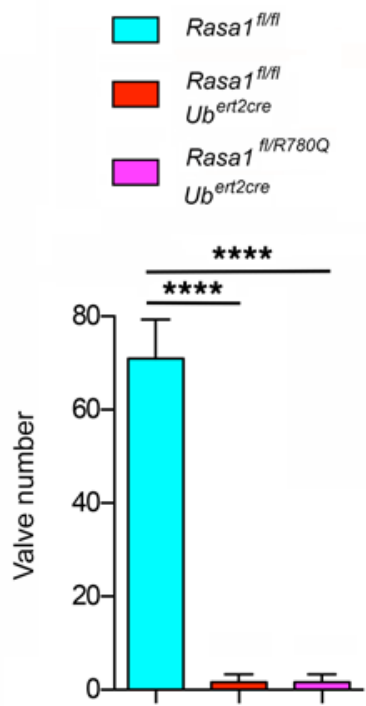

Figure 8. Blocked LV valve development in induced RASA1-deficient and induced Rasa $\mathbf{1}^{\text {R780 }}$ embryos. Embryos of the indicated genotypes were administered tamoxifen at E15.5. Mesenteries were harvested at E19.5 and stained with antibodies against PROX1, CD31, and integrin $\alpha-9$ to visualize LV valves. (A) Shown are merged confocal microscopic images of CD31 and PROX1 staining. Note lack of increased PROX1 staining at points of vessel bifurcation in

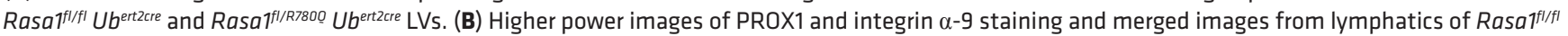
and Rasa ${ }^{f l / f l} U b^{\text {ertzcre }}$ mice. Note absence of integrin $\alpha-9$ staining in the Rasa $f^{f / f f} U b^{\text {ertzcre }}$ lymphatics. (C) Quantitation of LV valves in mesenteries of mice of the indicated genotypes ( $n=3$ each genotype). ${ }^{* * *} P<0.0001$, Student's 2 -sample $t$ test.

ically, therefore, the lymphatic valve dysfunction that develops in induced RASA1-deficient mice could be consequent to loss of either function of RASA1. To address this, we used a Rasa1 ${ }^{R 780 Q}$ knockin mouse strain that we reported recently (12). Arginine 780 of RASA1 is the "arginine finger" of the GAP domain that is essential in order for RASA1 to promote Ras hydrolysis of GTP (26). Mutation of this residue to a glutamine abrogates catalytic activity, but leaves all other putative functions of RASA1 intact (27). Homozygous Rasa1 ${ }^{R 780 Q}$ mice die at E10.5 as a consequence of abnormal BV development (12). Thus, we generated heterozygous Rasa1 ${ }^{f / / R 780 Q} U^{\text {ert } 2 \text { cre }}$ mice (Figure 6A). In the absence of tamoxifen, these mice develop normally and remain healthy throughout life, consistent with the fact that heterozygous Rasa1 ${ }^{+/-}$and Rasa1 $^{+/ R 780 Q}$ mice are also normal $(10,12)$. Mice were then crossed with Rasal ${ }^{f / l f l}$ mice to generate littermate Rasal ${ }^{f / R 780 Q} U b^{\text {ert2cre }}$ and Rasal ${ }^{f l / f l} U b^{\text {ert2cre }}$ mice and corresponding Rasal $^{f / R 780 Q}$ and Rasa1 ${ }^{l / f l}$ controls. At 3 to 4 weeks of age, mice were administered tamoxifen, resulting in either expression of Rasa1 ${ }^{R 780 Q}$ alone or complete loss of expression of Rasa1 in the respective $U b^{\text {ert2cre }}$ strains. Starting at several weeks after tamoxifen administration, Rasa1 $1^{f / R 780 Q} U b^{\text {ert2cre }}$ and Rasa1 $1^{f l / f l} U b^{\text {ert2cre }}$ mice both developed and succumbed to chylothorax (Figure 6B). Chylothorax was confirmed by flow cytometric analysis of pleural exudates that revealed a high content of $\mathrm{T}$ and $\mathrm{B}$ lymphocytes (Figure 6C). The time to development of chylothorax was similar between the 2 strains and perhaps even accelerated in Rasa1 $1^{f / R 780 Q} U b^{\text {ert2cre }}$ mice. Potentially, accelerated chylothorax in Rasa1 ${ }^{f / R 780 Q} U b^{\text {ert2cre }}$ mice could be explained on the grounds that the Cre recombinase needed only to cut and splice 1 rather than 2 Rasa1 $^{f l}$ alleles in order to create loss of functional RASA1 within LECs (Figure 6B). Staining of the chest wall of moribund tamoxifen-treated Rasa1 ${ }^{f / R 780 Q} U^{\text {ert2cre }}$ mice with anti-LYVE-1 antibody revealed an abundance of LVs facing the pleural cavity, comparable to those observed in moribund Rasa1 ${ }^{f / f l} U b^{\text {ert } 2 \text { cre }}$ mice 
A
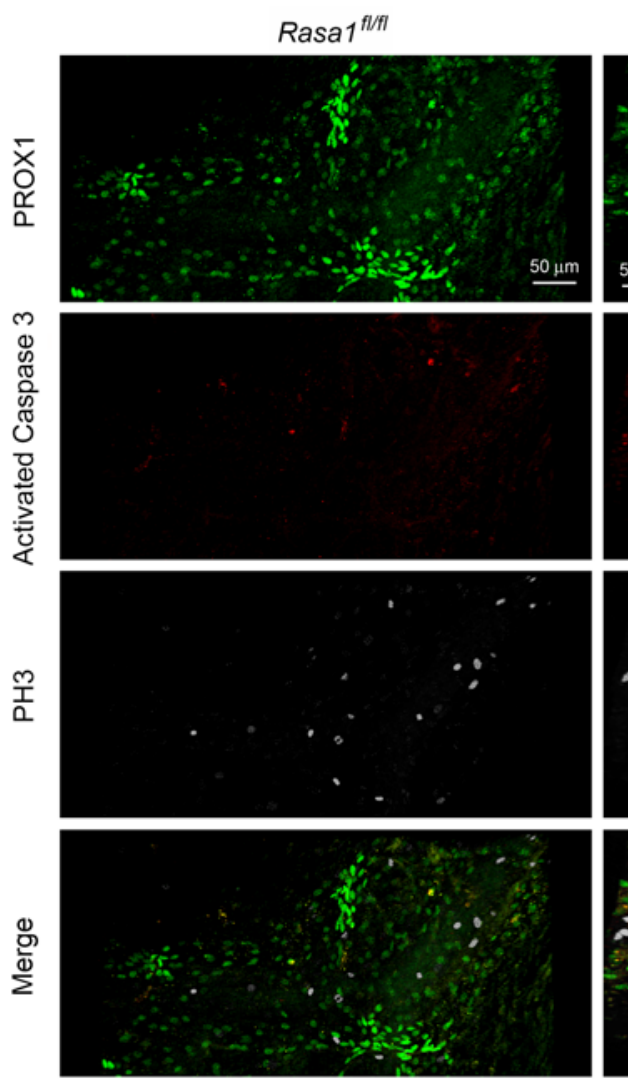

B

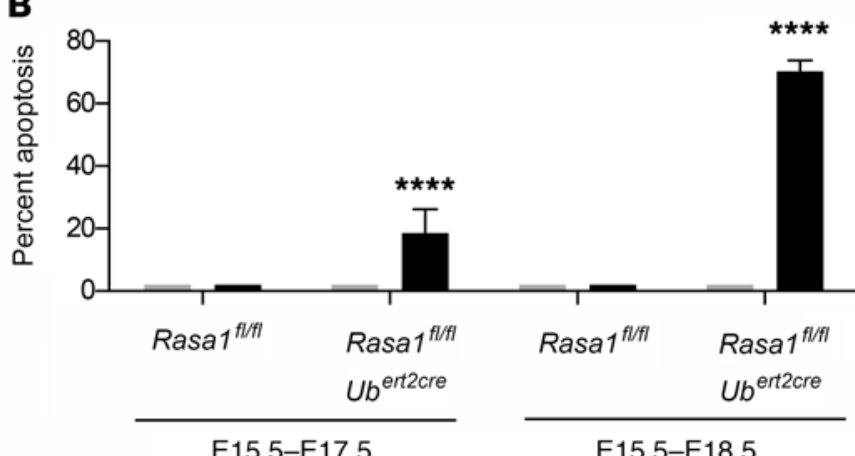

E15.5-E17.5
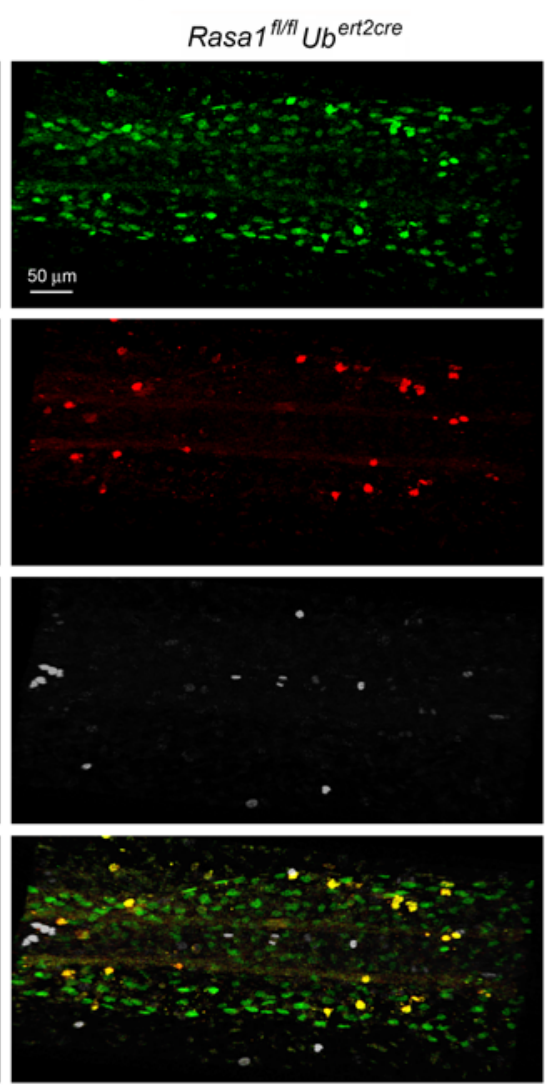

E15.5-E18.5
Figure 9. Apoptosis of PROX1 ${ }^{\text {hi }}$ LECs in developing LV valves of induced RASA1-deficient embryos.

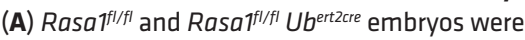

administered tamoxifen at E15.5. Mesenteries were harvested at E18.5 and stained with antibodies against PROX1, activated caspase 3 , and PH3.

Shown are confocal microscopic images of individual and merged antibody stains of representative mesenteric $L V$ valve regions from the 2 types of mice. Note that the majority of PROX ${ }^{\text {hi }}$ LECs in mesenteric LVs of Rasaft/ffl $U b^{\text {ertzcre }}$ embryos are stained with the anti-activated caspase 3 antibody and are in the process of apoptosis. (B) Percentage + SEM of apoptotic PROX $1^{10}$ and PROX1hi LECs in mesenteric LV valve regions of Rasa $f^{f / f l}$ and Rasaf $f^{f / f l} U b^{\text {ertzcre }}$ embryos at E17.5 and E18.5 ( $n=3$ to 9 analyzed valve regions for each genotype and time point of analysis). ${ }^{* * *} P<0.0001$, Student's 2-sample $t$ test. See also Supplemental Figure 7, which shows LEC staining patterns at E17.5 and E19.5. that we reported previously (Figure 6D) (11). LVs are sparse in this region of control mice. In conclusion, findings indicate that the chylothorax and LV hyperplasia that develop in RASA1-deficient mice are primarily a consequence of loss of a Ras-regulating function of RASA1 in LECs.

$L V$ valve dysfunction in induced Rasa $1^{R 780 Q}$ knockin mice. We next examined the pumping function of popliteal collecting LVs from Rasa1 ${ }^{f / R 780 Q} U^{\text {ert2cre }}$ mice at different times after tamoxifen treatment. Vessels from mice treated with tamoxifen 5 and 12 weeks previously behaved similarly to vessels from tamoxifen-treated Rasa1 ${ }^{f / R 780 Q}$ controls and had normal pump limits (Figure 6E). This is in contrast to vessels from Rasa1 ${ }^{f l / f l} U b^{\text {ert2cre }}$ mice that were unable to pump fluid against adverse pressure gradients when tested at 9 weeks after tamoxifen treatment (Figure 1B). However, when examined at 17 to 24 weeks after tamoxifen treatment, vessels from Rasa1 $1^{f / R 780 Q} U^{\text {ert2cre }}$ mice were also unable to pump against adverse pressure (Figure 6E). Thus, development of impaired pump function appears to be delayed in Rasal ${ }^{7 / R 780 Q} U b^{\text {ert2cre }}$ mice compared with Rasa1 ${ }^{f l / f l} U^{\text {ert2cre }}$ mice.

To examine this further, we performed valve-closure and low-pressure back-leak tests on vessels from Rasa1 ${ }^{f / R 780 Q} \mathrm{Ub}^{\text {ert2cre }}$ mice. At 12 weeks after tamoxifen treatment, 2 out of 4 tested valves behaved normally and closed in response to low adverse pressures across all tested initial vessel diameters. The remaining 2 valves showed a partial closure defect evidenced by a requirement for relatively high adverse pressures for closure at low vessel diameters (Figure 6F). However, across all vessel diameters, valves always closed within the range of adverse pressures that were examined. Again, this is in contrast to valves from Rasa1 ${ }^{f / f l} U b^{\text {ert } 2 \text { cre }}$ mice examined at 9 weeks after tamoxifen treatment, where all 
A
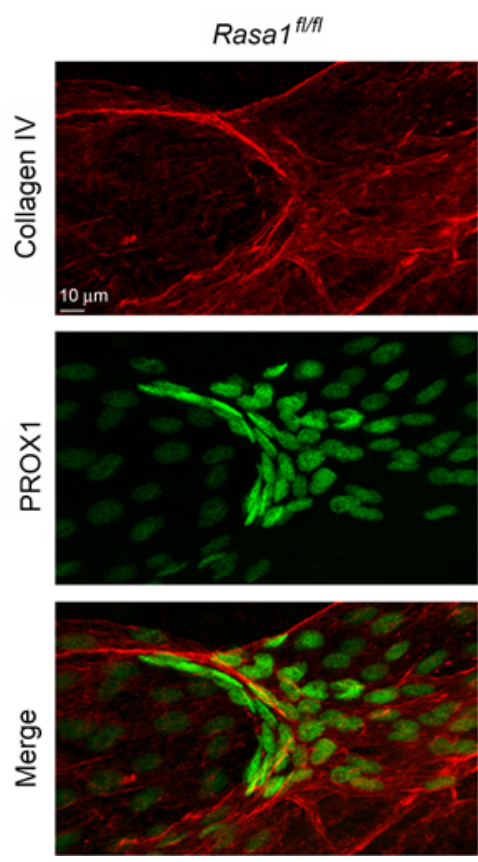

E15.5 TM-E17.5 TM analysis
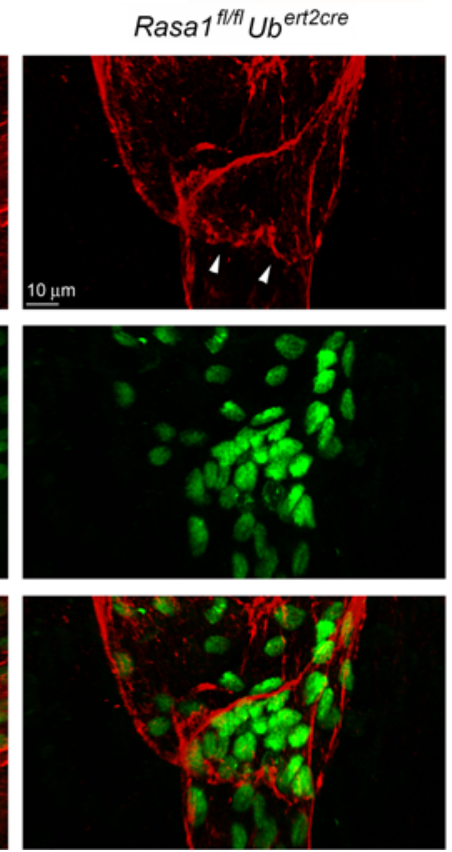

B

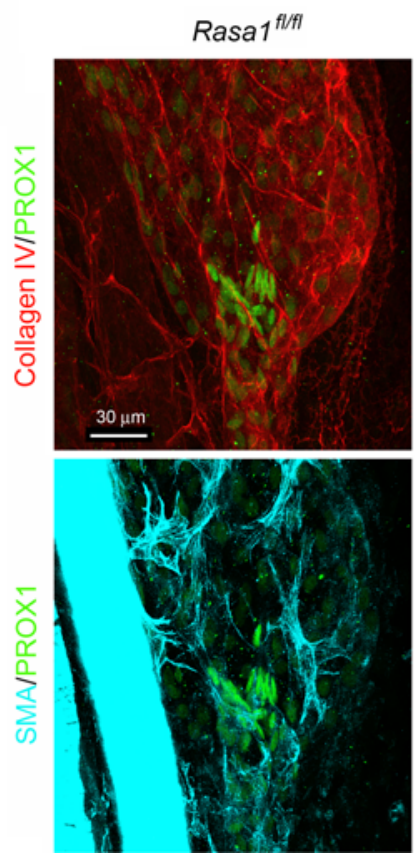

E15.5 TM-E19.5 TM analysis

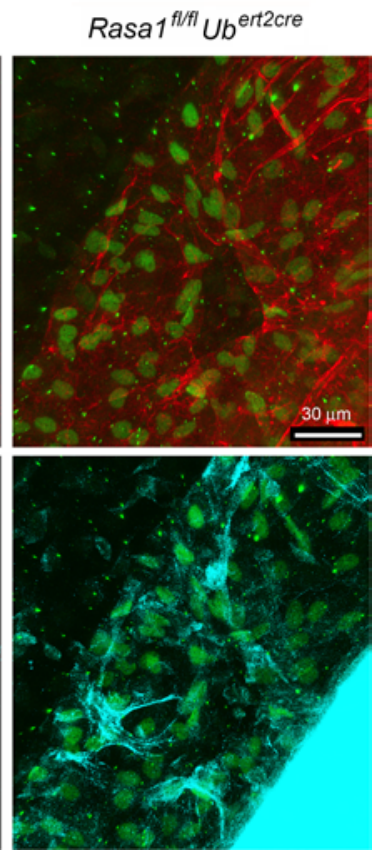

Figure 10. Discontinuous ECM in developing LV valve leaflets of induced RASA1-deficient embryos. Rasa ${ }^{f / f f}$ and $R a s a 1^{f l / f l} U b^{\text {ertzcre }}$ embryos were administered tamoxifen at E15.5. (A) Mesenteries were harvested at E17.5 and stained with antibodies against PROX1 and collagen IV. Shown are representative confocal microscopic images of individual and merged antibody staining. Note the discontinuous collagen IV staining in the developing leaflet of the valve in the Rasa $f^{f / f f} U^{\text {ertzcre }}$ LVs (arrowheads). See also Supplemental Figure 8, which highlights apoptotic LECs in the same leaflet of the Rasaffl/fl $U b^{\text {ertzcre }}$ vessel. (B) Mesenteries were harvested at E19.5 and stained with antibodies against PROX1, collagen IV, and smooth muscle actin (SMA). Shown are confocal images of merged PROX1 and collagen IV staining and merged PROX1 and SMA staining of representative valve regions and expected valve regions in Rasa ${ }^{f l / f l}$ and

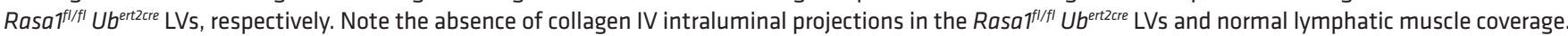

tested valves failed to close at any tested adverse pressure across all diameters (Figure 2, B and C). A valve-closure defect was more pronounced in Rasal ${ }^{f / R 780 Q} \mathrm{Ub}^{\text {ert2cre }}$ mice at 17 to 24 weeks after tamoxifen treatment. Thus, 4 out of 6 tested valves failed to close at any tested adverse pressure and diameter, 1 required abnormally high pressures to close at low vessel diameters and did not close at high vessel diameters, and 1 behaved normally (Figure 6F). All valves from control Rasa1 $1^{f / R 780 Q}$ mice treated with tamoxifen 16 to 25 weeks beforehand behaved normally in valve closure assays (Figure 6F).

Consistent with data from valve-closure tests, in low-pressure back-leak tests, valves from Rasa1 ${ }^{f / R 780 Q} U b^{\text {ert2cre }}$ mice treated with tamoxifen 5 and 12 weeks beforehand were able to resist transfer of pressure to the upstream lumen (Figure 6G and Supplemental Video 8). In contrast, all 5 valves from Rasa1 $1^{f / R 780 Q} \mathrm{Ub}^{\text {ert2cre }}$ mice treated with tamoxifen 17 to 24 weeks previously that failed to close in valve-closure tests were unable to resist back-flow in low-pressure back-leak tests (Figure 6G). Analysis of video recordings of these tests confirmed that leakage was consequent to defective valve closing (Supplemental Video 9).

Reduced LV valve leaflet length largely accounts for valve dysfunction in induced RASA1-deficient mice. Popliteal LV valve leaflets from tamoxifen-treated Rasa1 ${ }^{f / f l} U b^{\text {ert } 2 \text { re }}$ mice showed reduced length and cellularity compared with popliteal LV valve leaflets from tamoxifen-treated Rasa1 $1^{f / f l}$ littermate control mice (Figure $5, \mathrm{D}-\mathrm{F})$. To confirm the contribution of reduced leaflet length to valve dysfunction, for all popliteal valves from Rasa1 ${ }^{f / f l} U b^{\text {ert2cre }}$ and Rasa1 ${ }^{f / f l}$ mice that were assayed in low-pressure back-leak tests, we plotted mean leaflet length (average of the 2 leaflets) versus Psn pressure at a $\mathrm{P}_{\text {out }}$ of $10 \mathrm{~cm} \mathrm{H}_{2} \mathrm{O}$ (Figure 7A). This analysis revealed a threshold mean leaflet length of popliteal LV valves of approximately 90-100 $\mu \mathrm{m}$, below which valves were unable to resist backflow. All valves from Rasa ${ }^{f l / f l} \mathrm{Ub}^{\text {ertzcre }}$ mice treated with tamoxifen 9 and 16 weeks beforehand were at or below this threshold length and all were unable to resist back-flow. In contrast, all valves from control Rasa1 ${ }^{f / f l}$ mice were at or above this threshold and all resisted back-flow. Valves from Rasa $1^{f l f l} \mathrm{Ub}^{\text {ert2cre }}$ mice treated with tamoxifen 1 week beforehand showed variability in ability to resist backflow that largely correlated inversely with leaflet length, again centered at the 90-100 $\mu \mathrm{m}$ threshold (Figure 7A). An exception was 1 valve with a mean leaflet length of approximately $120 \mu \mathrm{m}$ that showed moderate leakage (Figure 7A). Therefore, whereas in the majority of cases, valve leakage can be explained by reduced leaflet length, at an early time point after tamoxifen treatment, an additional mechanism may contribute to valve dysfunction.

To obtain information on the number of $\mathrm{PROX}^{+}$cells per valve leaflet that are required to maintain leaflet length above a functional threshold in popliteal LVs, we plotted $\mathrm{PROX}^{+}$cell numbers per leaflet against leaflet length (half of the leaflet outer perimeter) for different popliteal LV valves from Rasal ${ }^{f / f l}$ and Rasaf ${ }^{l / f l} U b^{\text {ert2cre }}$ mice (treated with tamoxifen 5 weeks earlier) as determined in confocal imaging experiments (Figure 5F). From a 

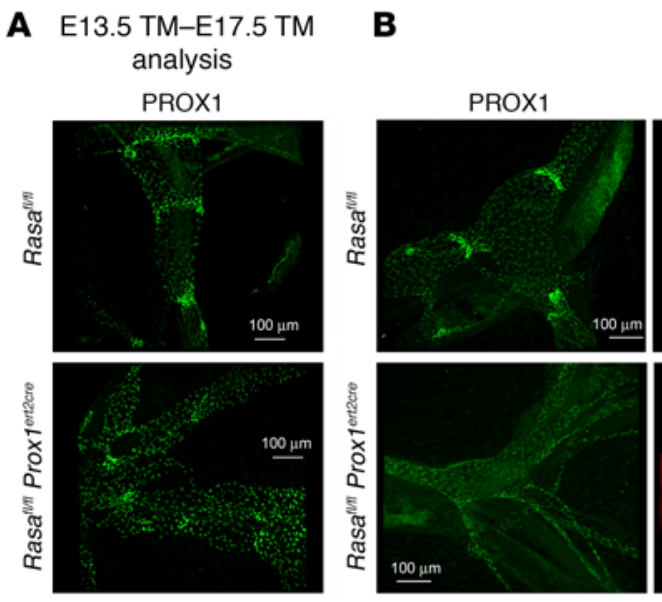

E13.5 TM-E19.5 TM

analysis

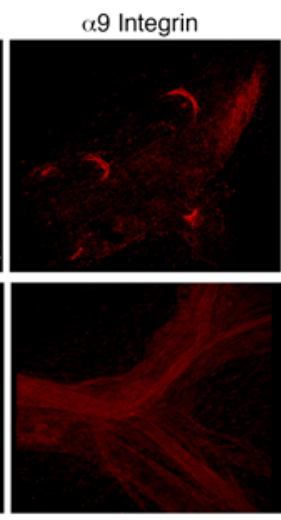

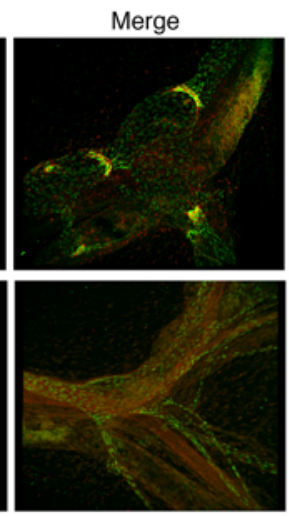

C

E13.5 TM-E19.5 TM analysis

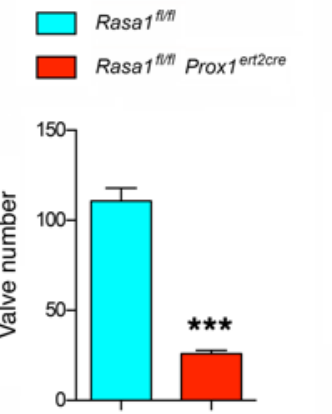

D
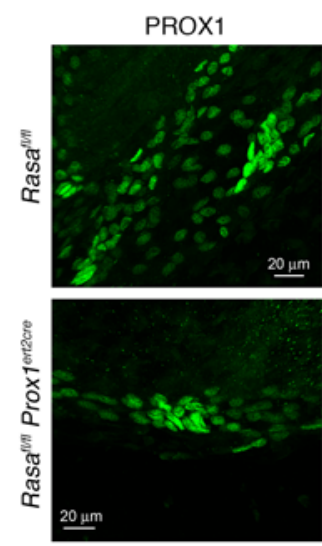

E15.5 TM-E18.5 TM analysis
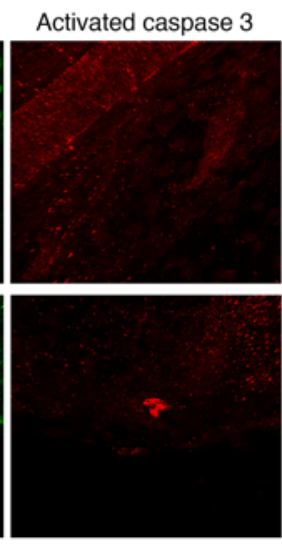
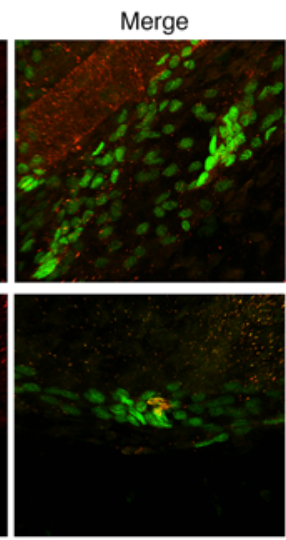

E

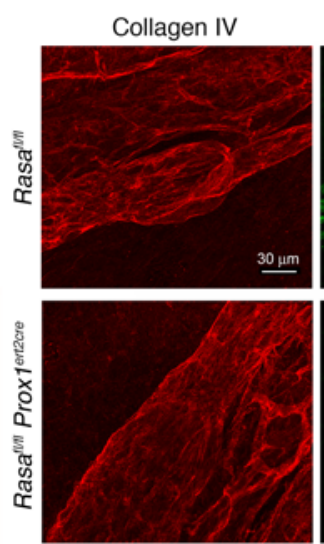

E15.5 TM-E18.5 TM analysis

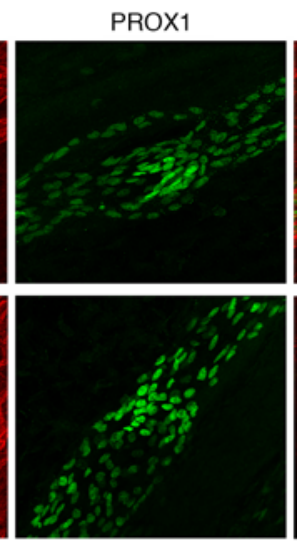

Merge

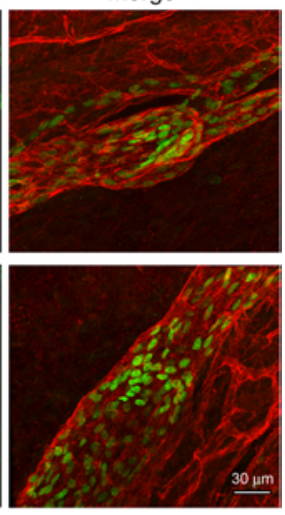

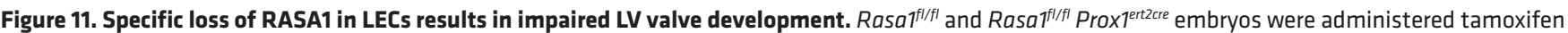
at E13.5. (A) Mesenteries were harvested at E17.5 and stained with an antibody against PROX1. Confocal microscope images show increased expression of

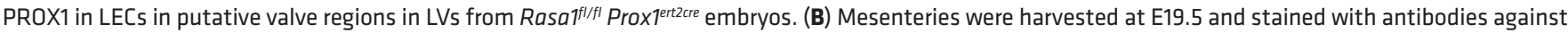
PROX1 and integrin $\alpha-9$. Shown are confocal images of individual and merged antibody staining. Note absence of valves in LVs of Rasa ${ }^{f / / f l}$ Prox ${ }^{\text {ertzcre }}$ embryos. (C) Quantitation of LV valves in tamoxifen-treated Rasa $7^{f / f l}$ and Rasa fl/ffl Prox fertzcre embryos at E19.5 ( $n=3$ each genotype). ${ }^{* * *} P<0.005$, Student's 2-sample $t$ test. (D and E) Mesenteries were harvested at E18.5 and stained with antibodies against PROX1 and activated caspase 3 (D) or PROX1 and collagen IV (E). Shown are confocal images of individual and merged antibody staining. Note apoptotic PROX ${ }^{\text {hi }}$ LECs (D) and much reduced leaflet collagen IV in LVs of the Rasaffl/fl Proxfertzcre embryos.

linear regression analysis of this plot, it is estimated that functional popliteal LV valve leaflets (at or greater than 90-100 $\mu \mathrm{m}$ length) contain at least approximately 11-14 $\mathrm{PROX}^{+}$cells (Figure 7B).

A threshold functional valve length of $90-100 \mu \mathrm{m}$ was also apparent in analyses of popliteal LV valves from tamoxifen-treated

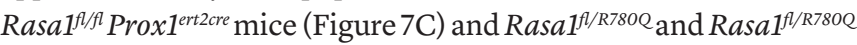

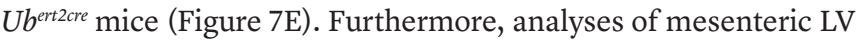
valves from tamoxifen-treated Rasa $1^{f / f l}$ and Rasa1 ${ }^{f / f l}$ Prox $1^{\text {ert2cre }}$ mice revealed a similar threshold functional valve leaflet length (Figure 7D). One popliteal LV valve from a Rasa1 ${ }^{f / f l}$ Prox $1^{\text {ert2cre }}$ mouse and 1 popliteal LV valve from a $R a s a 1^{f / R 780 Q} U b^{\text {ert2cre }}$ mouse had mean leaflet lengths above the threshold, but still leaked (Figure 7, C and E). Thus, for these valves, leakage must also be explained by an alternative mechanism.

Expression of the transcription factors GATA-2 and FOXC2 in LV valve leaflet LECs has been shown to be required for maintenance of valve structure and function in adults $(20,23)$. However, as shown by immunostaining of sections of popliteal LV valves from Rasa1 ${ }^{f / f l} U b^{\text {ert2cre }}$ mice treated with tamoxifen 1 or 10 weeks beforehand, expression of both transcription factors and PROX1 in valve leaflet LECs was not diminished following loss of RASA1 (Supplemental Figure 3). Theoretically, reduced numbers of LECs in LV valves could be explained by reduced proliferation of leaflet LECs or loss of LECs from leaflets. By immunostaining using an antibody against phosphohistone $\mathrm{H} 3$ ( $\mathrm{PH} 3$ ), we were unable to detect any proliferating LECs in valve leaflets or the vessel wall of popliteal LV valves of either Rasal ${ }^{f / f l}$ or Rasa1 ${ }^{f / / f l} U b^{\text {ert2cre }}$ mice following administration of tamoxifen (Supplemental Figure 3). Therefore, while we cannot formally exclude a contribution of reduced proliferation of leaflet LECs or vessel wall LECs to LV valve atrophy in induced RASA1-deficient mice, turnover of leaflet LECs even in adult RASA1-sufficient mice appears to be negligible. Loss of LECs from valve leaflets could be caused by impaired LEC intercellular adhesion or adhesion to the leaflet ECM core. No difference in the expression level or distribution of the VE-cadherin and ZO1 cell-adhesion junction proteins, which are involved 
in LEC intercellular adhesion, was observed for leaflet LECs between tamoxifen-treated Rasa1 ${ }^{f l / f l}$ and Rasa1 ${ }^{f / / f l} U b^{\text {ertacre }}$ mice (Supplemental Figure 4 and data not shown) $(28,29)$. Furthermore, we did not observe any difference in the ability of cultured LECs from tamoxifen-treated Rasa1 ${ }^{f / f l}$ and Rasa1 ${ }^{f / f l} U b^{\text {ert2cre }}$ mice to adhere to the ECM proteins laminin, collagen, or fibronectin in in vitro adhesion assays (Supplemental Figure 5). Therefore, any changes in the intrinsic ability of RASA1-deficient LECs to engage in intercellular or ECM adhesion are unlikely to account for LEC loss from leaflets.

A still further possibility that might explain LEC loss is apoptotic cell death following RASA1 loss. Given that 5 weeks after tamoxifen treatment, the average number of LECs in popliteal $\mathrm{LV}$ leaflets of Rasa1 ${ }^{\text {fl/fl }} \mathrm{Ub}^{\text {ertzcre }}$ mice is reduced by less than 6 cells compared with Rasa1 ${ }^{f / f l}$ mice, detection of LEC death in situ would be challenging (Figure 5F). In addition, it would be expected that apoptotic LECs would soon detach from leaflets as they are subjected to the shear forces of lymphatic flow. Nonetheless, through immunostaining of a large number of popliteal LV valves from tamoxifen-treated Rasa1 ${ }^{f / f l} \mathrm{Ub}{ }^{\text {ert2cre }}$ mice, a single leaflet LEC was detected that expressed an activated form of the caspase 3 enzyme in the cytoplasm that characterizes cells in the early process of apoptosis (Supplemental Figure 6).

RASA1 catalytic activity is required for the development of $L V$ valves. Since RASA1 is necessary for the maintenance of $L V$ valves in adults, we also asked whether it is required for formation of $\mathrm{LV}$ valves during embryonic development. $\mathrm{LV}$ valvulogenesis in mice is initiated at E16.5 and is characterized by increased expression of PROX1 in valve-forming LECs, commonly at sites of vessel bifurcation $(13,16)$. Therefore, we administered tamoxifen to pregnant Rasa1 $^{f / / f l}$ dams carrying Rasa $1^{f / f l}$ and Rasa1 ${ }^{f l / f l} U^{\text {ert2cre }}$ embryos to disrupt Rasa1 expression in the latter in advance of normal valvulogenesis. Strikingly, administration of tamoxifen to embryos at any time from E12.5 to E14.5 resulted in complete absence of the LV system in E19.5 embryos as a result of LEC apoptosis that occurred between E17 and E18 (data not shown). Therefore, in subsequent experiments, we administered tamoxifen at E15.5, 1 day in advance of normal valvulogenesis. Administration of tamoxifen to Rasa1 $1^{f / f l}$

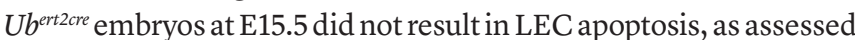
at E19.5. However, mesenteric LVs from these mice completely lacked valves, as indicated by the absence of LECs with increased expression of PROX1 (PROX1 $1{ }^{\text {hi }}$ LECs) and expression of the integrin $\alpha-9$ at points of vessel bifurcation (Figure $8, A-C$ ). Mesenteric LVs of the E15.5 tamoxifen-treated Rasa1 ${ }^{f l / f l} U b^{\text {ert2cre }}$ embryos sometimes appeared dilated, with increased numbers of cells (Figure 8A). However, failed valve development was not a consequence of vessel dilation, since valves also failed to develop in normal, smaller-sized LVs in these mice (not shown). We also examined LV valve development in Rasa1 $1^{f / R 780 Q} \mathrm{Ub}^{\text {ert2cre }}$ embryos treated with tamoxifen at E15.5. Similar to what occurred in the tamoxifen-treated Rasa1 $1^{f / f l}$ $U b^{\text {ert2cre }}$ embryos, valves failed to develop in mesenteric LVs of these embryos, as assessed at E19.5 (Figure 8, A and C). Therefore, failed valve development in the absence of RASA1 can be explained by loss of an ability of RASA1 to regulate Ras.

PROX $1^{\text {hi }}$ LECs undergo apoptotic cell death in developing $L V$ valves following loss of RASA1. To further understand the basis of failed LV valve development in the absence of RASA1, we exam- ined LEC PROX1 expression at earlier time points after tamoxifen administration as well as LEC proliferation and apoptosis in mesenteric LVs of tamoxifen-treated Rasa1 $1^{f / f l}$ and Rasa1 $1^{f / f l} U^{\text {ert } 2 \text { ree }}$ embryos. Tamoxifen was administered at E15.5 as before, and embryos were harvested at E17.5, E18.5, and E19.5. Mesenteries were then stained with antibodies against PROX1, PH3, and activated caspase 3. At E17.5, PROX1 ${ }^{\text {hi }}$ LECs were identified within putative valve-forming regions of mesenteric LVs of Rasa $1^{f / f l} \mathrm{Ub}^{\text {ert } 2 \text { cre }}$ mice. Notably, however, some of these PROX ${ }^{\text {hi }}$ LECs exhibited nuclear staining with anti-activated caspase 3 antibodies, indicating that they were undergoing apoptosis (Supplemental Figure 7). PROX $1^{\text {hi }}$ LECs were also identified in mesenteric LVs of Rasa1 $1^{f / f l}$ $U b^{\text {ertzcre }}$ mice at E18.5. However, at E18.5, the majority of PROX ${ }^{\text {hi }}$ LECs in mesenteric LVs of Rasal ${ }^{l / f l} \mathrm{Ub}^{\text {ert2cre }}$ mice were undergoing apoptosis (Figure 9). At E19.5, PROX $1^{\text {hi }}$ LECs were absent from mesenteric LVs of Rasa1 ${ }^{f / f l} U^{\text {ertacre }}$ mice, and few apoptotic LECs were observed (Supplemental Figure 7). Very few apoptotic LECs were observed in mesenteric LVs of Rasal ${ }^{f / f l}$ mice at any of the examined time points (Figure 9 and Supplemental Figure 7). Within LV valve-forming regions, no significant difference in the number of $\mathrm{PH}^{+}$cells was noted between Rasa1 $1^{f / f l}$ and Rasa1 $1^{f / f l}$ $U b^{\text {ert2cre }}$ mice at any time point after tamoxifen treatment (Figure 9 and Supplemental Figure 7). Therefore, absence of LV valves at E19.5 in Rasa ${ }^{f l / f l} U b^{\text {ert2cre }}$ mice treated with tamoxifen at E15.5 can be accounted for by death of PROX $1^{\text {hi }}$ LECs that occurs at E17.5 and E18.5. Coincident with apoptotic death of valve leaflet LECs at E17.5, the distribution of collagen IV in the ECM of developing valve leaflets was discontinuous in Rasa1 $1^{f l / f l} U b^{\text {ert } 2 \text { cre }}$ mice compared with that observed in LV valves of Rasa1 ${ }^{f / f l}$ control mice at this time point (Figure 10A and Supplemental Figure 8). At E19.5, valve leaflet-associated lumenal collagen IV projections observed in tamoxifen-treated Rasa1 ${ }^{f / / f l}$ mice could not be detected in tamoxifen-treated Rasa ${ }^{f / f l} U b^{\text {ertacre }}$ mice in regions where valve formation would otherwise be expected (Figure 10B). However, lymphatic muscle coverage in these regions was comparable between the 2 types of mice (Figure 10B).

Loss of RASA1 within LECs results in impaired development of $L V$ valves. To examine whether defects in $L V$ valve development in tamoxifen-treated Rasa1 ${ }^{f / f l} U b^{\text {ert } 2 \text { cre }}$ embryos result from loss of RASA1 within LECs, we also examined LV valvulogenesis in Rasa1 ${ }^{f l / f l}$ Prox $1^{\text {ert2cre }}$ mice. In initial experiments, we discovered that administration of tamoxifen at E13.5 to Rasa1 $1^{f l / f l}$ Prox $^{\text {ert2cre }}$ mice did not result in apoptotic death of all LECs, as observed in Rasa1 $1^{f / f l}$ $U b^{\text {ertzcre }}$ embryos. Therefore, in all subsequent experiments, tamoxifen was administered at E13.5 to Rasa1 ${ }^{f / f l}$ Prox ${ }^{\text {ert2cre }}$ mice, 3 days in advance of the onset of valvulogenesis. This strategy would permit a more robust assessment of the contribution of RASA1 to the earliest stages of LV valve development. Notably, at E17.5, PROX1 expression was increased in select LECs of Rasa1 ${ }^{f / f l}$ Prox $1^{\text {ertzcre }}$ LVs (Figure 11A). This finding indicates that RASA1 is not required for early LV valvulogenesis. However, at E19.5, there were 75\% fewer LV valves in Rasa1 $1^{f / f l}$ Prox $1^{\text {ert } 2 \text { cre }}$ mice compared with Rasa1 $1^{f / f l}$ mice (Figure 11, B and C). Therefore, loss of RASA1 specifically in LECs results in impaired development of mature LV valves. As in LVs from tamoxifen-treated Rasa1 ${ }^{f l / f l} U b^{\text {ert2cre }}$ embryos, at E18.5, PROX $1^{\text {hi }}$ LECs in LVs from Rasa1 ${ }^{f / f l}$ Prox $1^{\text {ert } 2 \text { cre }}$ mice but not Rasa1 $1^{f / f l}$ embryos were frequently observed to stain with anti-activated 
caspase 3 antibody, indicating apoptosis (Figure 11D). In addition, intralumenal projections of collagen IV were much less frequently observed in LVs of Rasa1 ${ }^{f / f l}$ Prox $1^{\text {ert2cre }}$ embryos at E18.5 compared with controls, and for those valves that were identified at E18.5, the amount of collagen IV in valve leaflets was less compared with that in control valve leaflets (Figure 11E).

\section{Discussion}

Although CM-AVM was initially described as a BV disorder, a significant number of patients have now been reported with additional lymphatic abnormalities that include lymphatic leakage (chylothorax, chylous ascites, lymphedema) and lymphatic hyperplasia (2-6). Consistent with these reports, induced loss of RASA1 in adult mice also results in lymphatic leakage (chylothorax and chylous ascites) and hyperplasia (11). However, the origin of these lymphatic abnormalities in either species, particularly lymphatic leakage, has remained uncertain. Based on our earlier observation of retrograde flow of injected tracer dyes in NIRFLI studies, in the current study, we explored the possibility that RASA1 is required for the function of intraluminal valves that prevent lymph backflow in collecting LVs of normal individuals $(13,14)$. We show that in adult mice, induced loss of RASA1 results in dysfunctional valves that are unable to close properly and prevent back-leak in response to adverse intraluminal pressure. Consequently, RASA1-deficient collecting LVs are ineffective pumps despite the fact that the contractile activity of vessels is unaffected by RASA1 loss. The valve closure defect results from loss of RASA1 specifically within LECs and is explained by net loss of LECs from valve leaflets, resulting in leaflet shortening below a critical threshold length of 90-100 $\mu \mathrm{m}$ corresponding to 11-14 PROX1+ LECs per leaflet for afferent popliteal LVs. Adult mice that are induced to express R780Q RASA1 in the absence of WT RASA1 develop the same LV valve abnormalities, but with a delayed time of onset compared with induced RASA1-deficient mice. This finding indicates that RASA1 contributes to LV valve function both by acting as a negative regulator of Ras and through participation in other distinct signaling pathways. In addition to its requirement for normal valve function in adults, RASA1 expressed within LEC was shown to be necessary for LV valve development in late embryogenesis. However, in contrast to valve maintenance, no evidence was obtained of a role for RASA1 in valve development that was independent of its GAP activity.

The finding that RASA1 is required for valve function and development provides at least part of an explanation for the lymphatic leakage defects that are observed in CM-AVM patients and RASA1-deficient mice. Furthermore, it is possible that at least part of the LV hyperplasia observed in both species is secondary to the valve defect and represents a homeostatic lymphangiogenic response intended to absorb accumulating interstitial fluid or lymph in tissues or body cavities. In agreement with this possibility, valve defects can be detected as soon as 1 week after RASA1 loss (Figure 3). In contrast, as shown in NIRFLI studies, the earliest time that LV hyperplasia can be detected is 2 weeks after gene disruption $(4,11)$. Furthermore, in light of the present findings, it is possible that any apparent hyperplasia at 2 weeks in NIRFLI studies does not represent hyperplasia per se, but back flow of dye into preexisting LVs. To obtain additional evidence that valve defects precede the onset of hyperplasia, we stained diaphragms from the same mice that exhibited severe defects in mesenteric $L V$ valve function (Figure 4) with antibodies against PROX1 and CD31. In these mice, LV hyperplasia was not apparent (Supplemental Figure 9).

LV hyperplasia in induced RASA1-deficient mice can be inhibited by continuous administration of blocking anti-VEGFR3 antibodies to mice (11). Our earlier interpretation of this finding is that RASA1 normally functions as a negative regulator of VEGFR3 signaling that prevents Ras activation in LV wall LECs triggered by its ligand VEGF-C, present at low concentrations in the extracellular space in unchallenged animals. In this interpretation, in the absence of RASA1, these low concentrations of VEGF-C would result in chronic activation of Ras in LECs and lymphangiogenesis. However, it is conceivable that dysregulated signaling through VEGFR3 on valve leaflet LECs in induced RASA1-deficient mice also contributes to the development of hyperplasia. Indeed, VEGFR3 is expressed at substantially higher levels on LECs in LV leaflets than on vessel wall LECs (30).

The notion that LV abnormalities in CM-AVM are primarily a result of valve dysfunction may also explain why LV abnormalities are restricted to a subset of patients. Presumably, in order for valve dysfunction or failed valve development to manifest, a critical number of valve leaflet LECs or valve-forming cells, respectively, would have to harbor inactivating second-hit mutations in the normal WT RASA1 allele. As a rare event, this is unlikely to be accomplished unless such mutations are acquired at an early point in vasculogenesis and specifically in cells that can give rise to valve-forming cells. Conversely, BV malformations could arise more frequently after second-hit mutation of RASA1 based on a less stringent requirement for multiple endothelial cells in a specific location to be affected. Whether impaired valve function and development is alone responsible for LV leakage in CM-AVM patients and induced RASA1-deficient mice remains to be determined. In this regard, it is of note that, although development of valve dysfunction is delayed in induced Rasa1 ${ }^{R 780 Q}$ mice compared with induced RASA1-deficient mice, the development of chylothorax occurs with similar kinetics and is perhaps even accelerated in the $\operatorname{Ras} 1^{R 780 Q}$ mice.

RASA1 does not appear to be required for the initial increased expression of PROX1 in early LV valvulogenesis (Figure 11). Rather, RASA1 is required for the survival of PROX ${ }^{\text {hi }}$ LECs in developing valves (Figures 9 and 11). Apoptotic death of PROX ${ }^{\text {hi }}$ LECs during LV valvulogenesis thus explains the absence of mature LV valves in induced RASA1-deficient embryos. Based upon this finding, it is likely that the net loss of LECs in LV valve leaflets of adult induced RASA1-deficient mice also results from increased LEC apoptotic death. This would be difficult to detect in vivo given the small number of LECs in each valve leaflet (average of 13 in valves of afferent popliteal collecting LVs) and the fact that LEC loss from leaflets is a slow process (loss of 5 to 6 LECs per leaflet over 5 weeks). Potentially, LV wall LECs could show similar increased susceptibility to apoptosis following loss of RASA1. However, LV wall LECs would not be subject to the increased shear forces experienced by valve leaflet LECs that might be necessary for net LEC loss in vivo.

The mechanism by which RASA1 loss results in apoptosis of LECs in developing and, potentially, mature valves is uncertain. One possibility is LEC detachment from the ECM that would trigger 
apoptotic death, a process referred to as anoikis (31). Detachment from the ECM could be caused by changes in the avidity of LEC adhesion receptors for ECM proteins. However, we were unable to detect any alteration in the ability of RASA1-deficient LECs to adhere to ECM proteins in vitro. Alternatively, detachment from the ECM could be caused by decreased synthesis or increased degradation of ECM proteins. This would be consistent with our finding of reduced amounts of collagen IV in developing valve leaflets and mature valves following loss of RASA1, although whether this is a cause of or consequence of leaflet LEC apoptosis is unknown. Another possibility is that RASA1 regulates LEC apoptosis directly. Interestingly, an antiapoptotic function of RASA1, which is mediated by an $\mathrm{N}$-terminal cleavage fragment of the molecule, has been reported previously $(32,33)$. However, it is unknown whether this antiapoptotic function of RASA1 requires GAP activity.

Finally, the findings reported here raise the possibility that defective valve function is the underlying cause of LV abnormalities in several different syndromic conditions known as RASopathies that are caused by inherited mutations in different genes that result in increased Ras signal transduction. These include Noonan syndrome (PTPN11, SOS1, KRAS, or RAF1 mutations), cardiofaciocutaneous syndrome (KRAS mutation), and Costello syndrome (HRAS mutation) $(34,35)$. LV abnormalities such as lymphedema, chylous ascites, and chylothorax are common in these diseases (36). In support of this possibility, in recent imaging studies of Noonan syndrome and cardiofaciocutaneous syndrome patients, retrograde flow of lymph in collecting LVs was observed frequently (37).

\section{Methods}

For a full description of Methods, see Supplemental Methods.

Mice. Rasa1 ${ }^{f / / f l}$ mice with and without $U b^{\text {ert2cre }}$ or Prox $1^{\text {1ert2cre }}$ transgenes and Rasaf $f^{f / R 780 Q}$ mice have been described $(11,12,38)$. The Prox $1^{\text {ert2cre }}$ transgenic line was provided by G. Oliver (Northwestern University Medical School, Chicago, Illinois, USA). Rasa1 ${ }^{7 / / R 780 Q}$ Ub $b^{\text {ert } 2 \text { cre }}$ mice were generated through crossbreeding. All mice were on a mixed 129S6/SvEv $\times$ C57BL/6 genetic background.

Statistics. Statistical analysis was performed using Student's 2 -sample $t$ test. A $P$ value of less than 0.05 was considered significant.

Study approval. All experiments performed with mice were in compliance with University of Michigan and University of Missouri guidelines and were approved by the respective university committees on the use and care of animals.

\section{Author contributions}

All authors contributed to the design of studies and conducted experiments. The manuscript was written by MJD and PDK.

\section{Acknowledgments}

This work was supported by NIH grants HL120888 (to PDK) and HL120867 (to MJD).

Address correspondence to: Philip D. King, Department of Microbiology and Immunology, University of Michigan Medical School, 6606 Med Sci II, 1150 West Medical Center Drive, Ann Arbor, Michigan 48109-5620, USA. Phone: 734.615.9073; Email: kingp@umich.edu.
1. Eerola I, et al. Capillary malformation-arteriovenous malformation, a new clinical and genetic disorder caused by RASA1 mutations. Am J Hum Genet. 2003;73(6):1240-1249.

2. Revencu N, et al. RASA1 mutations and associated phenotypes in 68 families with capillary malformation-arteriovenous malformation. Hum Mutat. 2013;34(12):1632-1641.

3. Revencu N, et al. Parkes Weber syndrome, vein of Galen aneurysmal malformation, and other fastflow vascular anomalies are caused by RASA1 mutations. Hum Mutat. 2008;29(7):959-965.

4. Burrows PE, et al. Lymphatic abnormalities are associated with RASA1 gene mutations in mouse and man. Proc Natl Acad Sci USA. 2013;110(21):8621-8626.

5. Macmurdo CF, et al. RASA1 somatic mutation and variable expressivity in capillary malformation/ arteriovenous malformation (CM/AVM) syndrome. Am JMed Genet A. 2016;170(6):1450-1454.

6. de Wijn RS, Oduber CE, Breugem CC, Alders M, Hennekam RC, van der Horst CM. Phenotypic variability in a family with capillary malformations caused by a mutation in the RASA1 gene. Eur J Med Genet. 2012;55(3):191-195.

7. King PD, Lubeck BA, Lapinski PE. Nonredundant functions for Ras GTPase-activating proteins in tissue homeostasis. Sci Signal. 2013;6(264):re1.

8. Kulkarni SV, Gish G, van der Geer P, Henkemeyer M, Pawson T. Role of p120 Ras-GAP in directed cell movement. J Cell Biol. 2000;149(2):457-470.

9. Conti E, Izaurralde E. Nonsense-mediated mRNA decay: molecular insights and mechanis- tic variations across species. Curr Opin Cell Biol. 2005;17(3):316-325.

10. Henkemeyer M, et al. Vascular system defects and neuronal apoptosis in mice lacking ras GTPase-activating protein. Nature. 1995;377(6551):695-701.

11. Lapinski PE, et al. RASA1 maintains the lymphatic vasculature in a quiescent functional state in mice. J Clin Invest. 2012;122(2):733-747.

12. Lubeck BA, et al. Blood vascular abnormalities in Rasa1(R780Q) knockin mice: implications for the pathogenesis of capillary malformation-arteriovenous malformation. Am J Pathol. 2014;184(12):3163-3169.

13. Bazigou E, Makinen T. Flow control in our vessels: vascular valves make sure there is no way back. Cell Mol Life Sci. 2013;70(6):1055-1066.

14. Bazigou E, Wilson JT, Moore JE. Primary and secondary lymphatic valve development: molecular, functional and mechanical insights. Microvasc Res. 2014;96:38-45.

15. Bazigou E, et al. Integrin-alpha9 is required for fibronectin matrix assembly during lymphatic valve morphogenesis. Dev Cell. 2009;17(2):175-186.

16. Sabine A, et al. Mechanotransduction, PROX1, and FOXC2 cooperate to control connexin 37 and calcineurin during lymphatic-valve formation. Dev Cell. 2012;22(2):430-445.

17. Sabine A, Petrova TV. Interplay of mechanotransduction, FOXC2, connexins, and calcineurin signaling in lymphatic valve formation. Adv Anat Embryol Cell Biol. 2014;214:67-80.

18. Tatin F, et al. Planar cell polarity protein Celsr1 regulates endothelial adherens junctions and directed cell rearrangements during valve morphogenesis. Dev Cell. 2013;26(1):31-44.

19. Danussi C, et al. EMILIN1/ $\alpha 9 \beta 1$ integrin interaction is crucial in lymphatic valve formation and maintenance. Mol Cell Biol. 2013;33(22):4381-4394.

20. Kazenwadel J, et al. GATA2 is required for lymphatic vessel valve development and maintenance. JClin Invest. 2015;125(8):2979-2994.

21. Norrmén C, et al. FOXC2 controls formation and maturation of lymphatic collecting vessels through cooperation with NFATc1. JCell Biol. 2009;185(3):439-457.

22. Kanady JD, Dellinger MT, Munger SJ, Witte MH, Simon AM. Connexin 37 and Connexin 43 deficiencies in mice disrupt lymphatic valve development and result in lymphatic disorders including lymphedema and chylothorax. Dev Biol. 2011;354(2):253-266.

23. Sabine A, et al. FOXC2 and fluid shear stress stabilize postnatal lymphatic vasculature. J Clin Invest. 2015;125(10):3861-3877.

24. Bazigou E, et al. Genes regulating lymphangiogenesis control venous valve formation and maintenance in mice. JClin Invest. 2011;121(8):2984-2992.

25. Scallan JP, Wolpers JH, Davis MJ. Constriction of isolated collecting lymphatic vessels in response to acute increases in downstream pressure. JPhysiol (Lond). 2013;591(2):443-459.

26. Scheffzek K, et al. The Ras-RasGAP complex: structural basis for GTPase activation and its loss in oncogenic Ras mutants. Science. 1997;277(5324):333-338. 
27. Miao W, Eichelberger L, Baker L, Marshall MS. p120 Ras GTPase-activating protein interacts with Ras-GTP through specific conserved residues. J Biol Chem. 1996;271(26):15322-15329.

28. Baluk P, et al. Functionally specialized junctions between endothelial cells of lymphatic vessels. JExp Med. 2007;204(10):2349-2362.

29. Dejana E, Tournier-Lasserve E, Weinstein BM. The control of vascular integrity by endothelial cell junctions: molecular basis and pathological implications. Dev Cell. 2009;16(2):209-221.

30. Lohela M, Bry M, Tammela T, Alitalo K. VEGFs and receptors involved in angiogenesis versus lymphangiogenesis. Curr Opin Cell Biol.
2009;21(2):154-165.

31. Michel JB. Anoikis in the cardiovascular system: known and unknown extracellular mediators. Arterioscler Thromb Vasc Biol. 2003;23(12):2146-2154.

32. Yang JY, et al. Partial cleavage of RasGAP by caspases is required for cell survival in mild stress conditions. Mol Cell Biol. 2004;24(23):10425-10436.

33. Yang JY, Widmann C. Antiapoptotic signaling generated by caspase-induced cleavage of RasGAP. Mol Cell Biol. 2001;21(16):5346-5358.

34. Tartaglia M, Zampino G, Gelb BD. Noonan syndrome: clinical aspects and molecular pathogenesis. Mol Syndromol. 2010;1(1):2-26.

35. Tidyman WE, Rauen KA. The RASopathies: developmental syndromes of Ras/MAPK pathway dysregulation. Curr Opin Genet Dev. 2009;19(3):230-236.

36. Sevick-Muraca EM, King PD. Lymphatic vessel abnormalities arising from disorders of Ras signal transduction. Trends Cardiovasc Med. 2014;24(3):121-127.

37. Joyce $S$, et al. The lymphatic phenotype in Noonan and Cardiofaciocutaneous syndrome. Eur J Hum Genet. 2016;24(5):690-696.

38. Lapinski PE, Bauler TJ, Brown EJ, Hughes ED, Saunders TL, King PD. Generation of mice with a conditional allele of the p120 Ras GTPase-activating protein. Genesis. 2007;45(12):762-767. 